\title{
Clinical Pharmacokinetics and Pharmacodynamics of Immune Checkpoint Inhibitors
}

\author{
Maddalena Centanni ${ }^{1}$ - Dirk Jan A. R. Moes ${ }^{2} \cdot$ Iñaki F. Trocóniz ${ }^{3} \cdot$ Joseph Ciccolini $^{4} \cdot$ J. G. Coen van Hasselt ${ }^{1}$ (i)
}

Published online: 28 February 2019

(c) The Author(s) 2019

\begin{abstract}
Immune checkpoint inhibitors (ICIs) have demonstrated significant clinical impact in improving overall survival of several malignancies associated with poor outcomes; however, only $20-40 \%$ of patients will show long-lasting survival. Further clarification of factors related to treatment response can support improvements in clinical outcome and guide the development of novel immune checkpoint therapies. In this article, we have provided an overview of the pharmacokinetic (PK) aspects related to current ICIs, which include target-mediated drug disposition and time-varying drug clearance. In response to the variation in treatment exposure of ICIs and the significant healthcare costs associated with these agents, arguments for both dose individualization and generalization are provided. We address important issues related to the efficacy and safety, the pharmacodynamics (PD), of ICIs, including exposure-response relationships related to clinical outcome. The unique PK and PD aspects of ICIs give rise to issues of confounding and suboptimal surrogate endpoints that complicate interpretation of exposure-response analysis. Biomarkers to identify patients benefiting from treatment with ICIs have been brought forward. However, validated biomarkers to monitor treatment response are currently lacking.
\end{abstract}

\section{Key Points}

The pharmacokinetics (PK) of immune checkpoint inhibitors (ICIs) are subject to target-mediated drug position and time-varying drug clearance. Moderate to high interindividual variability in PK can currently be explained, only to some extent, by differences in patientspecific characteristics.

Surrogate clinical endpoints for ICIs lack predictive value for overall survival.

Novel immune activation biomarkers are of relevance to further optimize treatment and trial designs with respect to the PK and pharmacodynamics of ICIs.

Electronic supplementary material The online version of this article (https://doi.org/10.1007/s40262-019-00748-2) contains supplementary material, which is available to authorized users.

J. G. Coen van Hasselt

coen.vanhasselt@lacdr.leidenuniv.nl

1 Division of Systems Biomedicine and Pharmacology, Leiden Academic Centre for Drug Research, Leiden University, Einsteinweg 55, 2333 CC Leiden, The Netherlands

2 Department of Clinical Pharmacy and Toxicology, Leiden University Medical Center, Leiden, The Netherlands

\section{Introduction}

Immune checkpoint inhibitors (ICIs) have greatly improved the prognosis of melanoma, nonsmall cell lung cancer (NSCLC), urothelial carcinoma and a variety of other malignancies [1-4]. At present, six ICIs have been approved by the US Food and Drug Administration (FDA), of which five ICIs also received market authorization by the European Medicines Agency (EMA).

Immune checkpoints comprise a group of regulatory surface proteins that are entrenched within the immune system and are crucial to prevent autoimmune responses [5]. ICIs target these immune checkpoints in order to stimulate T-cell-mediated killing of tumor cells (Fig. 1) [6]. Current immune checkpoints targeted by ICIs include cytotoxic

3 Pharmacometrics and Systems Pharmacology, Department of Pharmacy and Pharmaceutical Technology, School of Pharmacy and Nutrition, University of Navarra, Pamplona, Spain

4 SMARTc, CRCM Inserm U1068 Aix Marseille Univ and La Timone University Hospital of Marseille, Marseille, France 
T-lymphocyte-associated antigen 4 (CTLA-4), the programmed death 1 (PD-1) receptor and the programmed cell death-ligand 1 (PD-L1) [5, 7]. In addition to these proteins, other co-stimulatory and co-inhibitory receptors are being targeted in clinical trials, such as GITR, OX40, 4-1BB, LAG-3 and TIM-3 [8]. In the current review, we focus only on those ICIs that received regulatory approval.

Although ICIs play a crucial role in the treatment of various malignancies, limited attention has been attributed to treatment optimization and individualization of ICIs. Variation in both exposure and individual response may allow to further optimize these treatments in individual patients and to address the significant healthcare costs associated with these agents [9]. To this aim, understanding the pharmacokinetic (PK) and pharmacokinetic-pharmacodynamic (PKPD) properties in terms of efficacy and safety of ICIs is essential.

Despite their different mechanisms of action, ICIs are mostly humanized or human immunoglobulin (Ig) G1 antibodies (except anti PD-1, which are IgG4) displaying approximately the same PK properties as other therapeutic monoclonal antibodies (mAbs), which includes little or no impact of renal and liver function impairment, limited

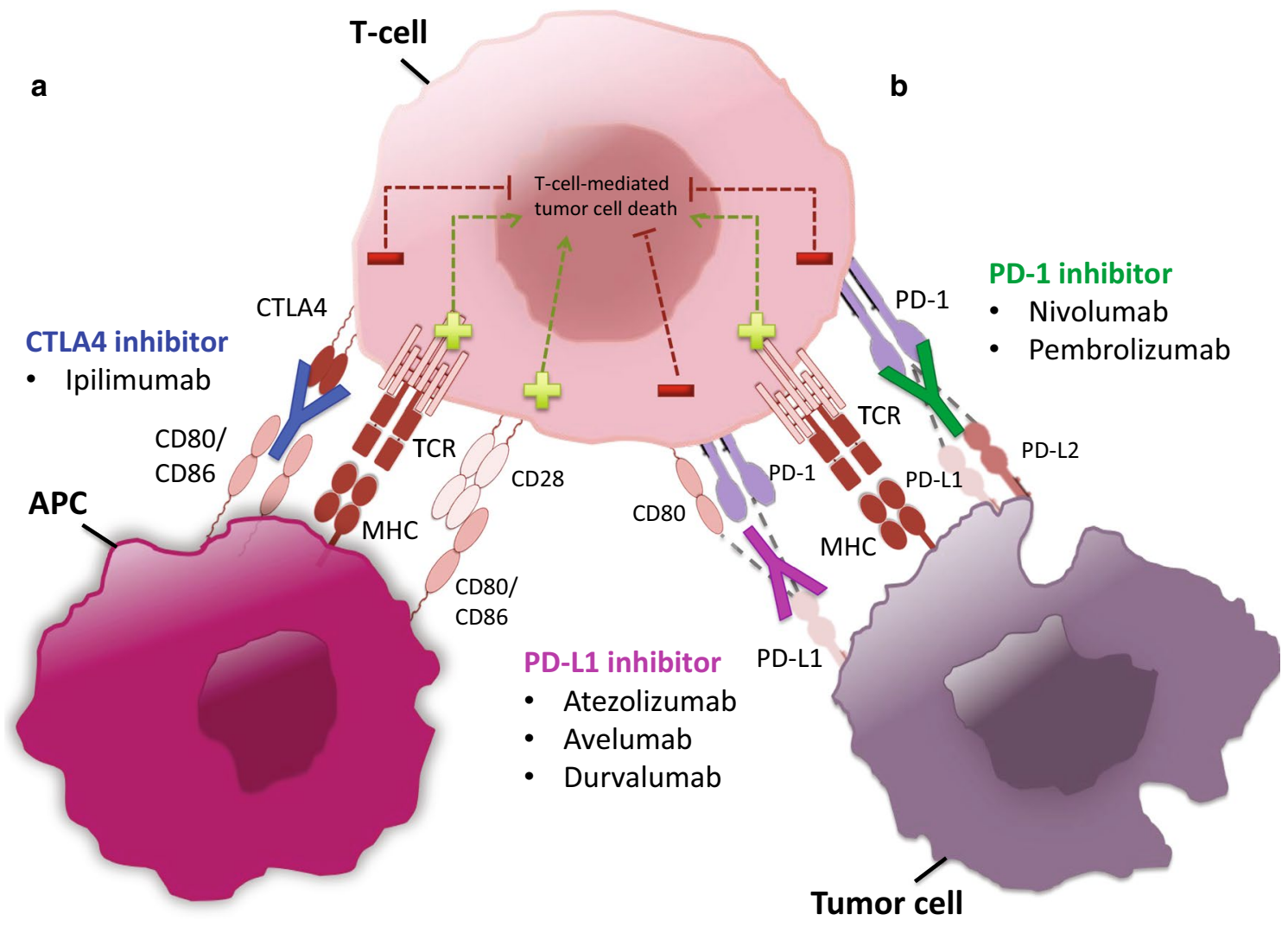

Fig. 1 Molecular targets of ICIs. Tumor cells have the capacity to override the host immune system and hamper antitumor reaction. One means by which this occurs is by dampening T-cell response. Inhibition of T-cells can transpire at various stages of their antitumor response and arises upon activation of suppressor surface receptors by their respective ligands [114]. ICIs have been tailored to antagonize this reaction by binding to inhibitory proteins involved in the supression of antitumor reactions, thereby liberating the host immune reaction against tumor cells. Priming phase: In the priming phase, naïve $\mathrm{T}$ cells in the lymphoid organs become exposed to tumor-specific antigens, resulting in the differentiation of naïve $T$ cells into effector T cells (e.g. Treg, cytotoxic T cells and helper T cells). This represents the initial step of an adaptive reaction against tumor cells, which is supported by the co-stimulatory effect of the CD28 receptor with CD80/86. The effect of CD28 becomes restrained in the presence of the CTLA-4 receptor, which holds a much higher affin- ity for the CD80/86 ligands. CTLA-4-blocking antibodies hamper this constraint and restore the formation of effector $\mathrm{T}$ cells to generate an antitumor response. Moreover, anti-CTLA-4 antibodies might be involved in the depletion of CTLA- 4 expressing Treg cells in the tumor microenvironment. Effector phase: In the effector phase, cytotoxic $\mathrm{T}$ cells in the tumor microenvironment eliminate tumor cells by means of cell-to-cell communication. This reaction becomes dampened by the interactions between the PD-1 receptor on $\mathrm{T}$ cells and PD-L1, or, to a lesser degree, PD-L2, proteins on the surface of tumor cells and host myeloid cells (i.e. macrophages) in the tumor microenvironment [115]. Antagonism of PD-1 or PD-L1 by ICIs maintains T-cell effect and reinstates T-cell response against tumor cells. APC antigen-presenting cell, $M H C$ major histocompatibility complex, $T C R$ T-cell receptor, CD80/86 cluster of differentiation 80/86, Treg regulatory T cell, ICIs immune checkpoint inhibitors, $P D-1$ programmed death $1, P D-L 1$ programmed death-ligand 1 
diffusion out of the vascular space, a long half-life and receptor-mediated clearance with a combined linear plus nonlinear phase [10]. Consequently, the PK and inter- and intrapatient variability with ICIs can be mediated through the synthesis of anti-mAb, tumor burden effects, changes in proteolytic function and genetic polymorphisms affecting the neonatal $\mathrm{Fc}$ receptor $(\mathrm{FcRn})$.

As all ICIs have only recently been approved, only limited data are available regarding the PK/PD relationships of ICIs. Most knowledge is based on registration trials performed in selected patient cohorts. After the first mAbs (e.g. bevacizumab, trastuzumab, cetuximab) were approved in oncology, it has taken years of clinical practice to understand that PK considerations could be of equal relevance as somatic biomarkers to predict clinical outcome [11, 12]. For ICIs, knowledge of the exposure-response relationships and how they can be anticipated/predicted by available biomarkers can support treatment improvement and patient selection. In addition, characterization of the sources of difference between ICIs and the relevance of different surrogate endpoints in clinical trials could improve the development of future compounds. To this end, the current review provides a comprehensive overview of the clinical PK and PD of currently approved ICIs.

\section{Immune Checkpoint Inhibitors (ICls)}

\subsection{Ipilimumab}

Ipilimumab (Yervoy ${ }^{\circledR}$ ) is a human $\operatorname{IgG} 1 \mathrm{mAb}$ against CTLA-4 (Table 1). The compound is approved for the treatment of (unresectable) metastatic melanoma and is administered as four 90 -min infusions consisting of a $3 \mathrm{mg} / \mathrm{kg}$ dose each, once every 3 weeks. Additionally, ipilimumab is administered in combination with nivolumab in renal cell carcinoma, microsatellite instability-high (MSI-H) or mismatch repair deficient (dMMR) colorectal cancer, as four 30-min infusions consisting of $1 \mathrm{mg} / \mathrm{kg}$ each.

\subsubsection{Pharmacokinetics}

Ipilimumab clearance is linear over the dose range of $0.3-10 \mathrm{mg} / \mathrm{kg}$ and averages at $0.36 \mathrm{~L} /$ day (normalized to a $80-\mathrm{kg}$ body weight), with an interindividual variability (IIV) of $35.4 \%$ (Table 2) [13]. Factors that are related to clearance are body weight and baseline lactate dehydrogenase (LDH) levels, which, on average, account for only $24 \%$ of the variability in clearance [13]. Of note, the actual impact of LDH on ipilimumab clearance can be questioned because high LDH levels are usually associated with poor clinical outcome in patients with cancer. Consequently, several confounding factors and comorbidities, such as cachexia and hypoalbuminemia, frequently observed in patients with progressive disease can impact on the clearance of therapeutic $\mathrm{mAbs}$, as reported elsewhere [14]. The presence of antidrug antibodies (ADAs) was associated with an average increase in ipilimumab clearance of $22 \%$ [13], although only $5 \%$ of patients developed ADAs and their presence was often temporary. The average half-life of ipilimumab is estimated at 14.7 days, with steady state reached after 9 weeks [13]. Currently, ipilimumab is the only ICI where time-varying clearance has not been observed. The central and peripheral distribution volumes were estimated at $4.15 \mathrm{~L}$ (IIV 14.9\%) and $3.11 \mathrm{~L}$, respectively (normalized to a $80-\mathrm{kg}$ body weight) [13]. For the central compartment, body weight accounted for $52 \%$ of the IIV [13].

\subsubsection{Exposure-Efficacy Relationship}

Three studies investigated the effect between ipilimumab exposure and clinical outcomes for melanoma (NCT00135408, NCT00289627, and NCT00289640) (Table 3) [15]. In these studies, a total of 419 participants received ipilimumab at doses of $0.3,1,3$ or $10 \mathrm{mg} / \mathrm{kg}$. Clinical efficacy endpoints were objective response rate (ORR) [partial tumor response (PTR) or complete tumor response (CTR), according to the Response Evaluation Criteria in Solid Tumors version 1.1 (RECIST v1.1)], immune-related response criteria (irRC) and overall survival (OS). The analysis revealed that in comparison to dose, exposure is a more accurate predictor for OS [15]. Minimum concentration at steady state $\left(C_{\text {min,ss }}\right)$ was a significant predictor of all efficacy endpoints, as defined by ORR, irRC and OS, with a stronger correlation between $C_{\text {min,ss }}$ and irRC in comparison to $C_{\text {min,ss }}$ and ORR [15]. Ipilimumab dose was less closely, but also significantly, associated with OS [15].

\subsubsection{Exposure-Safety Relationship}

In 14 completed ipilimumab trials $(n=1498), 25.3 \%$ of patients developed one form of treatment-related grade 3-4 adverse events (AEs) [16]. Treatment-related deaths were reported for $0.9 \%$ of patients [16]. Another analysis including 22 ipilimumab trials $(n=1265)$ reported severe grade of immune-related AEs (irAEs). These represent a group of adverse effects that arise from immune system activation, including skin inflammation (pruritis, rash), gastrointestinal organs (hepatitis, colitis) and endocrine tissues (hypophysitis, thyroiditis) [4]. IrAEs were found in $17 \%$ and $31 \%$ of patients at ipilimumab doses of 3 and $10 \mathrm{mg} / \mathrm{kg}$, respectively [17]. The most prevalent adverse effects were gastrointestinal (5-14\%), endocrine (1-4\%), dermatological (1-2\%) and hepatic (0-1\%) irAEs (at $3 \mathrm{mg} / \mathrm{kg}$ ) [17]. Death related to irAEs was reported for a total of $0.86 \%$ of participants, most often due to colic bowel perforation [17]. 
Table 1 Summary of approved immune checkpoint inhibitors (as of April 2018)

\begin{tabular}{|c|c|c|c|c|c|c|}
\hline $\begin{array}{l}\text { Generic name } \\
\text { (receptor target) }\end{array}$ & $\begin{array}{l}\text { Marketing-authori- } \\
\text { zation holder }\end{array}$ & $\begin{array}{l}\text { Therapeutic indica- } \\
\text { tion }\end{array}$ & $\begin{array}{l}\text { Date of authoriza- } \\
\text { tion (FDA/EMA) }\end{array}$ & $\begin{array}{l}\text { Recommended dose } \\
\text { (FDA) }\end{array}$ & $\begin{array}{l}\text { Recommended dose } \\
\text { (EMA) }\end{array}$ & References \\
\hline \multirow[t]{3}{*}{$\begin{array}{l}\text { Ipilimumab (CTLA- } \\
\text { 4) }\end{array}$} & \multirow[t]{3}{*}{$\begin{array}{l}\text { Bristol-Myers } \\
\text { Squibb }\end{array}$} & Melanoma & $\begin{array}{l}\text { March 2011/July } \\
2011\end{array}$ & $\begin{array}{l}\text { Metastatic: } 3 \mathrm{mg} / \\
\mathrm{kg} ; 3 \text {-weekly (four } \\
\text { doses) } \\
\text { Adjuvant: } 10 \mathrm{mg} / \\
\mathrm{kg} ; 3 \text {-weekly (four } \\
\text { doses); followed } \\
\text { by } 12 \text {-weekly }\end{array}$ & $\begin{array}{l}3 \mathrm{mg} / \mathrm{kg} ; 3 \text {-weekly } \\
\text { (four doses) }\end{array}$ & {$[48]$} \\
\hline & & $\begin{array}{l}\text { Renal cell carci- } \\
\text { noma }\end{array}$ & $\begin{array}{l}\text { April 2018/Novem- } \\
\text { ber } 2018\end{array}$ & & $\begin{array}{l}1 \mathrm{mg} / \mathrm{kg} ; 3 \text {-weekly } \\
\text { (four doses) }\end{array}$ & {$[48]$} \\
\hline & & $\begin{array}{l}\text { Microsatellite } \\
\text { instability-high or } \\
\text { mismatch repair- } \\
\text { deficient cancer } \\
\text { Colorectal cancer }\end{array}$ & November 2018/- & & $\begin{array}{l}1 \mathrm{mg} / \mathrm{kg} ; 3 \text {-weekly } \\
\text { (four doses) }\end{array}$ & [48] \\
\hline \multirow[t]{2}{*}{$\begin{array}{l}\text { Atezolizumab (PD- } \\
\text { L1) }\end{array}$} & \multirow[t]{2}{*}{ Genentech/Roche } & $\begin{array}{l}\text { Urothelial carci- } \\
\text { noma }\end{array}$ & $\begin{array}{l}\text { May 2016/Septem- } \\
\text { ber } 2017\end{array}$ & 1200 mg; 3-weekly & 1200 mg; 3-weekly & [49] \\
\hline & & $\begin{array}{l}\text { Nonsmall cell lung } \\
\text { cancer }\end{array}$ & $\begin{array}{l}\text { October } 2016 / \text { Sep- } \\
\text { tember } 2017\end{array}$ & 1200 mg; 3-weekly & 1200 mg; 3-weekly & [49] \\
\hline \multirow[t]{2}{*}{ Avelumab (PD-L1) } & \multirow[t]{2}{*}{ Merck Serono } & $\begin{array}{l}\text { Merkel cell carci- } \\
\text { noma }\end{array}$ & $\begin{array}{l}\text { March } 2017 / \text { condi- } \\
\text { tional approval }\end{array}$ & $10 \mathrm{mg} / \mathrm{kg} ; 2$-weekly & 10 mg/kg; 2-weekly & {$[21]$} \\
\hline & & $\begin{array}{l}\text { Urothelial carci- } \\
\text { noma }\end{array}$ & May 2017/- & $10 \mathrm{mg} / \mathrm{kg} ; 2$-weekly & & {$[21]$} \\
\hline \multirow[t]{2}{*}{$\begin{array}{l}\text { Durvalumab (PD- } \\
\text { L1) }\end{array}$} & \multirow[t]{2}{*}{ AstraZeneca } & $\begin{array}{l}\text { Urothelial carci- } \\
\text { noma }\end{array}$ & May 2017/- & $10 \mathrm{mg} / \mathrm{kg} ; 2$-weekly & & {$[27]$} \\
\hline & & $\begin{array}{l}\text { Nonsmall cell lung } \\
\text { cancer }\end{array}$ & February 2018/- & $10 \mathrm{mg} / \mathrm{kg} ; 2$-weekly & & {$[27]$} \\
\hline \multirow[t]{8}{*}{ Nivolumab (PD-1) } & \multirow[t]{8}{*}{$\begin{array}{l}\text { Bristol-Myers } \\
\text { Squibb }\end{array}$} & Melanoma & $\begin{array}{l}\text { December 2014/ } \\
\text { June } 2015\end{array}$ & $\begin{array}{l}240 \mathrm{mg} \text {; } \\
\text { 2-weekly/480 mg; } \\
\text { 4-weekly }\end{array}$ & $3 \mathrm{mg} / \mathrm{kg} ; 2$-weekly & {$[31]$} \\
\hline & & $\begin{array}{l}\text { Nonsmall cell lung } \\
\text { cancer }\end{array}$ & $\begin{array}{l}\text { October } 2015 / \text { Octo- } \\
\text { ber } 2015\end{array}$ & $\begin{array}{l}240 \mathrm{mg} \text {; } \\
\text { 2-weekly/480 mg; } \\
\text { 4-weekly }\end{array}$ & $3 \mathrm{mg} / \mathrm{kg} ; 2$-weekly & {$[31]$} \\
\hline & & $\begin{array}{l}\text { Renal cell carci- } \\
\text { noma }\end{array}$ & $\begin{array}{c}\text { November 2015/ } \\
\text { February } 2016\end{array}$ & $\begin{array}{l}240 \mathrm{mg} \text {; } \\
\text { 2-weekly/480 mg; } \\
\text { 4-weekly }\end{array}$ & 3 mg/kg; 2-weekly & [31] \\
\hline & & $\begin{array}{l}\text { Classic Hodgkin } \\
\text { lymphoma }\end{array}$ & $\begin{array}{l}\text { May 2016/October } \\
2016\end{array}$ & $\begin{array}{l}240 \mathrm{mg} \text {; } \\
\text { 2-weekly/480 mg; } \\
\text { 4-weekly }\end{array}$ & 3 mg/kg; 2-weekly & {$[31]$} \\
\hline & & $\begin{array}{l}\text { Squamous cell } \\
\text { cancer of the head } \\
\text { and neck }\end{array}$ & $\begin{array}{l}\text { November 2016/ } \\
\text { March } 2017\end{array}$ & $\begin{array}{l}240 \mathrm{mg} \text {; } \\
\text { 2-weekly/480 mg; } \\
\text { 4-weekly }\end{array}$ & 3 mg/kg; 2-weekly & {$[31]$} \\
\hline & & $\begin{array}{l}\text { Urothelial carci- } \\
\text { noma }\end{array}$ & February 2017/- & $\begin{array}{l}240 \mathrm{mg} \text {; } \\
\text { 2-weekly/480 mg; } \\
\text { 4-weekly }\end{array}$ & & {$[31]$} \\
\hline & & $\begin{array}{l}\text { Microsatellite } \\
\text { instability-high or } \\
\text { mismatch repair- } \\
\text { deficient cancer } \\
\text { Colorectal Cancer }\end{array}$ & August 2017/- & 240 mg; 2-weekly & & {$[31]$} \\
\hline & & $\begin{array}{l}\text { Hepatocellular } \\
\text { carcinoma }\end{array}$ & September 2017/- & $\begin{array}{l}240 \mathrm{mg} \text {; } \\
\text { 2-weekly/480 mg; } \\
\text { 4-weekly }\end{array}$ & & {$[31]$} \\
\hline $\begin{array}{l}\text { Pembrolizumab } \\
\text { (PD-1) }\end{array}$ & Merck & Melanoma & $\begin{array}{l}\text { September 2014/ } \\
\text { July } 2015\end{array}$ & 200 mg; 3-weekly & $2 \mathrm{mg} / \mathrm{kg} ; 3$-weekly & [38] \\
\hline
\end{tabular}


Table 1 (continued)

\begin{tabular}{|c|c|c|c|c|c|c|}
\hline $\begin{array}{l}\text { Generic name } \\
\text { (receptor target) }\end{array}$ & $\begin{array}{l}\text { Marketing-authori- } \\
\text { zation holder }\end{array}$ & $\begin{array}{l}\text { Therapeutic indica- } \\
\text { tion }\end{array}$ & $\begin{array}{l}\text { Date of authoriza- } \\
\text { tion (FDA/EMA) }\end{array}$ & $\begin{array}{l}\text { Recommended dose } \\
\text { (FDA) }\end{array}$ & $\begin{array}{l}\text { Recommended dose } \\
\text { (EMA) }\end{array}$ & References \\
\hline & & $\begin{array}{l}\text { Nonsmall cell lung } \\
\text { cancer }\end{array}$ & $\begin{array}{l}\text { October 2015/ } \\
\text { December } 2016\end{array}$ & $200 \mathrm{mg}$; 3-weekly & $\begin{array}{l}200 \mathrm{mg} ; \\
\text { 3-weekly/2 mg/ } \\
\text { kg; 3-weekly }\end{array}$ & {$[38]$} \\
\hline & & $\begin{array}{l}\text { Squamous cell } \\
\text { cancer of the head } \\
\text { and neck }\end{array}$ & August 2016/- & $200 \mathrm{mg}$; 3-weekly & & [38] \\
\hline & & $\begin{array}{l}\text { Classical Hodgkin } \\
\text { lymphoma }\end{array}$ & $\begin{array}{l}\text { March 2017/March } \\
2017\end{array}$ & $200 \mathrm{mg}$; 3-weekly & 200 mg; 3-weekly & {$[38]$} \\
\hline & & $\begin{array}{l}\text { Urothelial carci- } \\
\text { noma }\end{array}$ & May 2017/July 2017 & 200 mg; 3-weekly & 200 mg; 3-weekly & {$[38]$} \\
\hline & & $\begin{array}{l}\text { Microsatellite } \\
\text { instability-high } \\
\text { cancer }\end{array}$ & May 2017/- & $200 \mathrm{mg}$; 3-weekly & & {$[38]$} \\
\hline & & Gastric cancer & September $2017 /-$ & $200 \mathrm{mg}$; 3-weekly & & [38] \\
\hline
\end{tabular}

FDA Food and Drug Administration, EMA European Medicines Agency, $P D-L 1$ programmed death-ligand 1, $P D-1$ programmed death-1

In an exposure-safety analysis that included four studies ( $n=498$; NCT00261365, NCT00135408, NCT00289627, and NCT00289640) (Table 4), $C_{\text {min,ss }}$ was identified as a significant predictor for irAEs [15].

\subsection{Atezolizumab}

Atezolizumab (Tecentriq ${ }^{\circledR}$ ) is a fully humanized $\operatorname{IgG} 1 \mathrm{mAb}$ that binds to PD-L1 and is currently approved for the treatment of NSCLC and urothelial carcinoma, with a PD-L1 expression $>5 \%$ (Table 1 ). Atezolizumab is administered as a $1200 \mathrm{mg}$ dose every 3 weeks, initially as a 60-min intravenous infusion, leading to a mean trough concentration at steady state $\left(C_{\mathrm{ss} \text {,trough }}\right)$ above the $6 \mu \mathrm{g} / \mathrm{mL}$ target serum concentration in phase I and II trials. If the infusion is tolerated, the drug can become administered as a 30-min infusion for the following treatment cycles.

\subsubsection{Pharmacokinetics}

Atezolizumab clearance has been found to be linear over a dose range of $1-20 \mathrm{mg} / \mathrm{kg}$ ( $n=428$ patients), including the $1200 \mathrm{mg}$ flat dose $(n=45)$ (Table 2$)$. The typical clearance is $0.200 \mathrm{~L} /$ day (normalized to a $77-\mathrm{kg}$ body weight), with an IIV of $29 \%$ [18]. Patient-specific factors could predict up to $15 \%$ of the IIV [18] and included serum albumin concentration, post-baseline ADA status, body weight and tumor burden. Interestingly, atezolizumab clearance was found to be decreased over time in a subgroup of patients, giving rise to higher exposures at later treatment. However, this was not investigated in PK analysis and therefore no clear data regarding the degree of changes in clearance, or the factors related to this phenomenon, are available [19]. The development of post-baseline ADAs increased clearance by
$16 \%$ on average, with $16.7-41.9 \%$ of patients developing ADAs among the reported trials [18]. The average half-life of atezolizumab is estimated at 27 days, with steady-state concentrations reached after 6-9 weeks [18]. The central and peripheral distribution volumes of atezolizumab have been estimated at $3.28 \mathrm{~L}$ and $3.63 \mathrm{~L}$ (normalized to a $77-\mathrm{kg}$ body weight), respectively [18]. IIV was estimated at $18 \%$ for the central compartment, of which only $5 \%$ could be explained by variation in patient-specific characteristics [18].

\subsubsection{Exposure-Efficacy Relationship}

The relationship between atezolizumab exposure and efficacy in urothelial carcinoma was evaluated for 306 participants in the IMvigor210 study (NCT02108652) (Table 3) [18]. Participants received atezolizumab as a fixed dose of $1200 \mathrm{mg}$ every 3 weeks for treatment of locally advanced or metastatic urothelial bladder cancer. The primary efficacy measure was the percentage of participants with PTR or CTR, according to RECIST v1.1. The analysis did not identify a significant exposure-efficacy relationship, with respect to area under the concentration-time curve (AUC) from time zero to $21 \mathrm{~h}\left(\mathrm{AUC}_{21}\right)$, AUC at steady state $\left(\mathrm{AUC}_{\mathrm{ss}}\right)$, maximum concentration $\left(C_{\mathrm{max}}\right)$ and $C_{\mathrm{min}}$, at various cycles of the treatment. Conversely, an exposure-efficacy analysis for NSCLC was evaluated for 653 individuals in the BIRCH study (NCT02031458) and identified a positive relationship between $\mathrm{AUC}_{\mathrm{ss}}$ and ORR [19].

\subsubsection{Exposure-Safety Relationship}

A total of $16 \%$ of participants suffered from at least one grade 3 or 4 treatment-related $\mathrm{AE}$, with the most prevalent AE being fatigue (3.4\%), increased alanine aminotransferase (3.4\%), and increased aspartate aminotransferase (2.5\%) [18, 


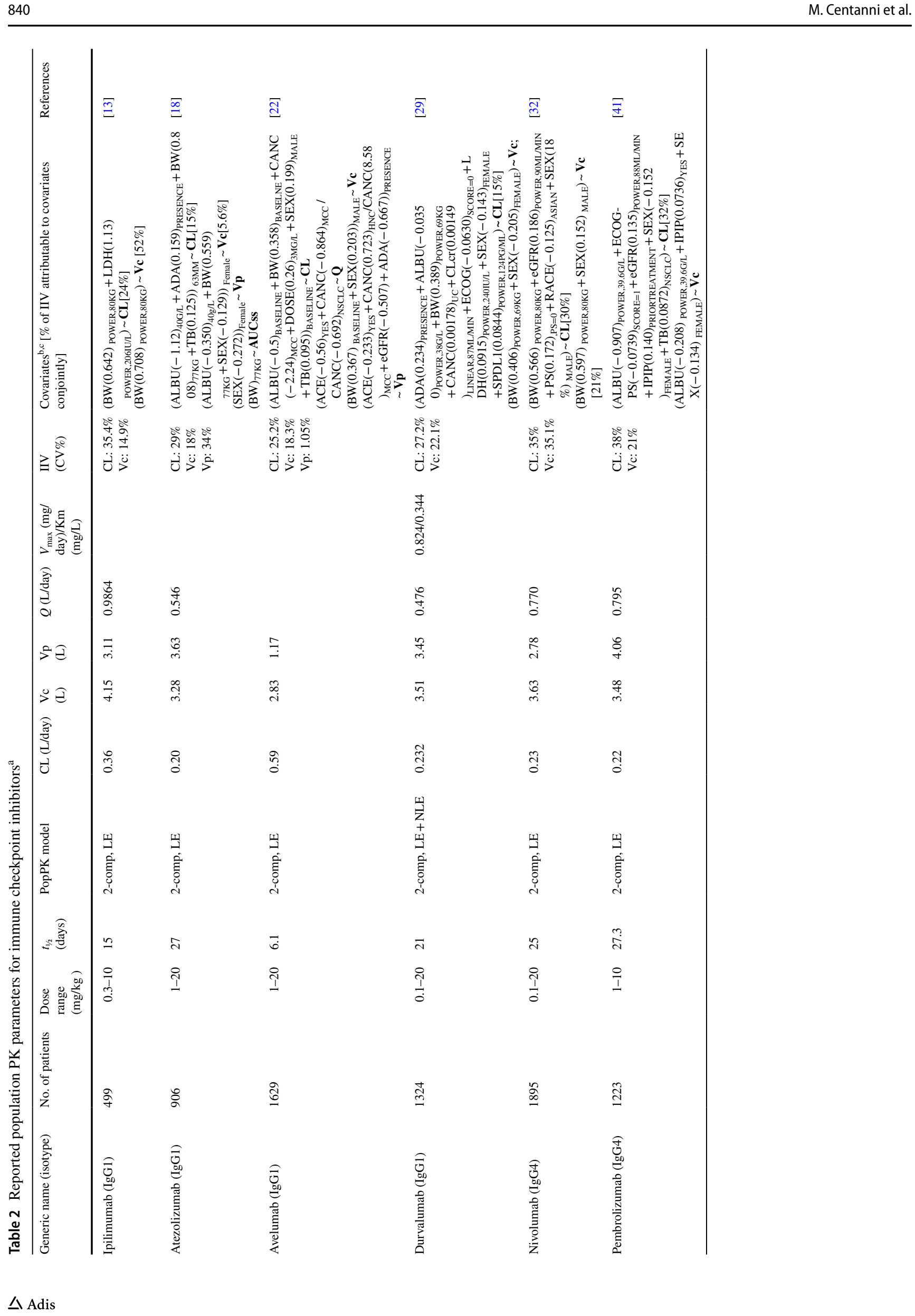




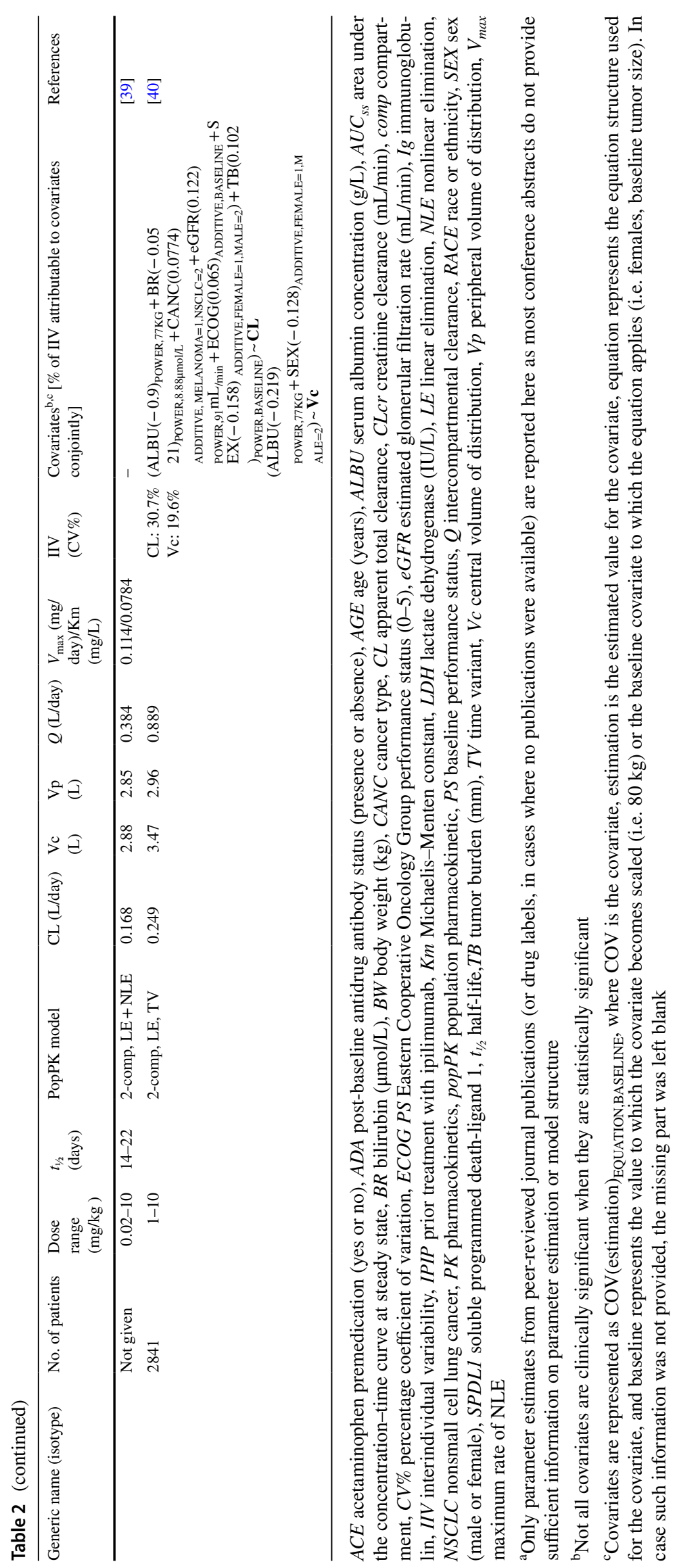




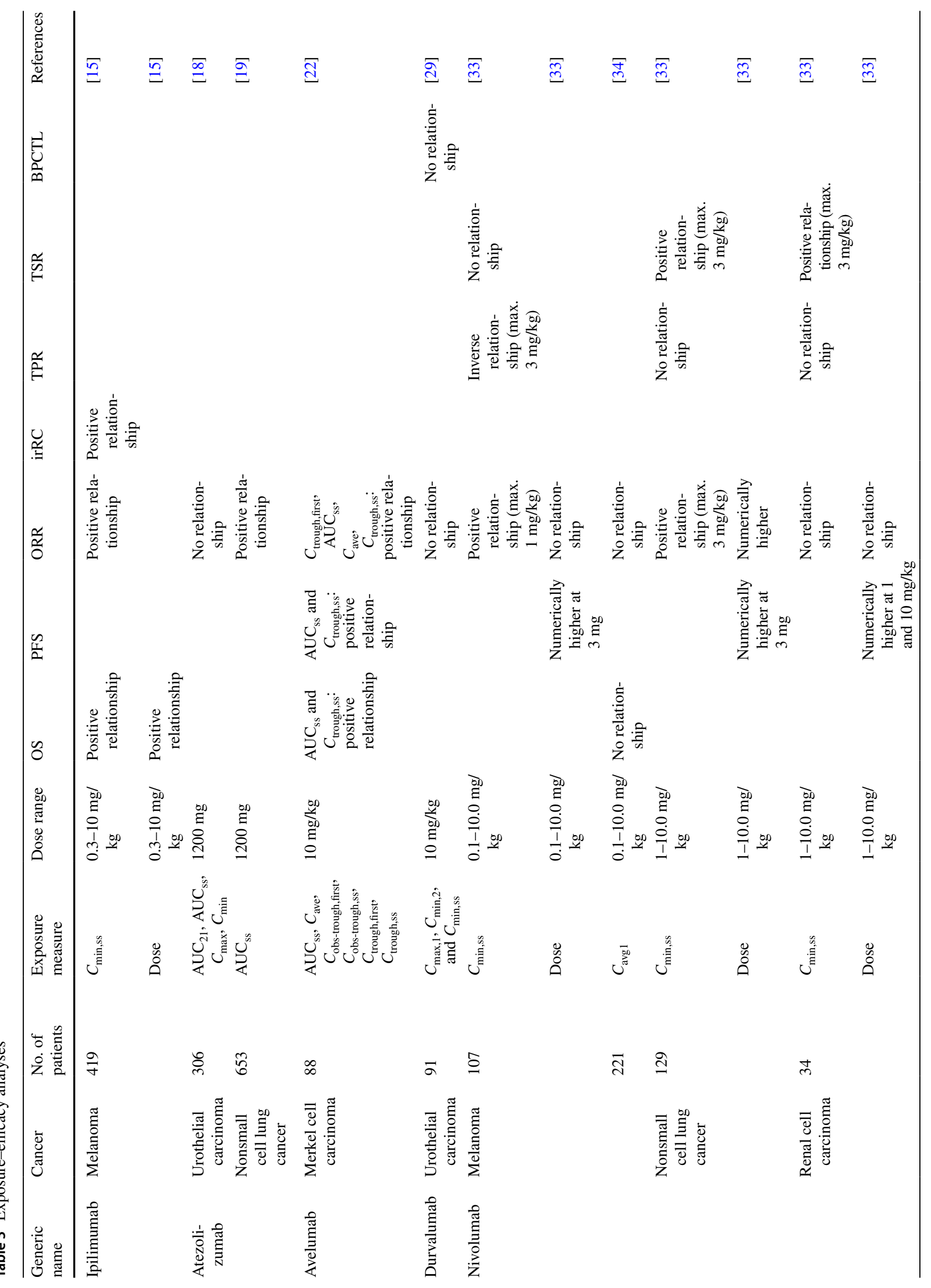




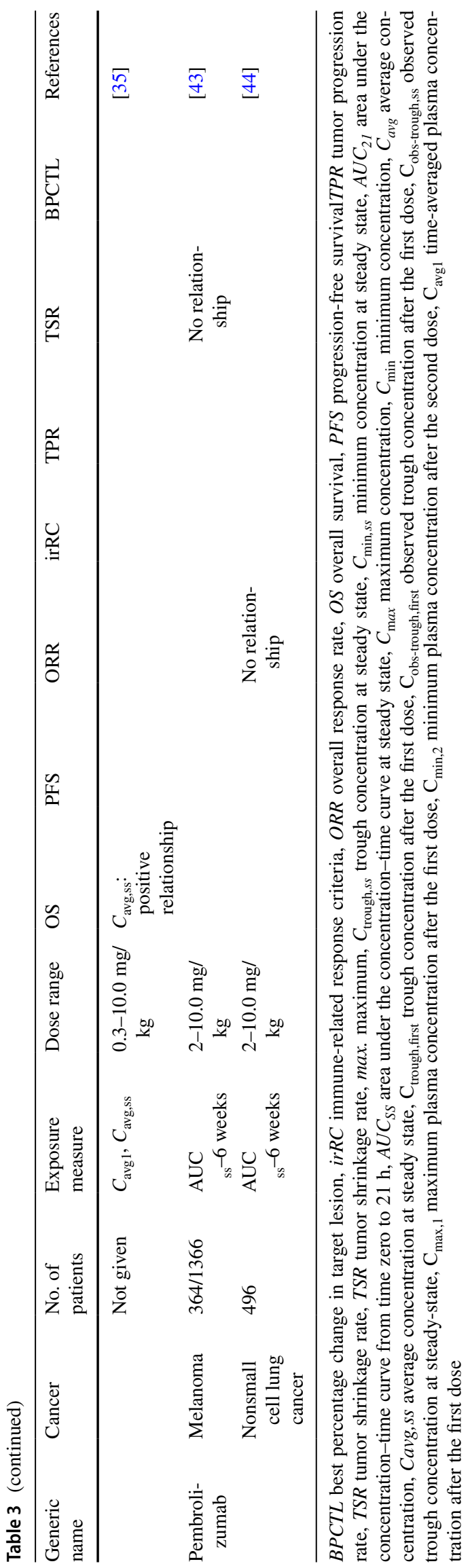

20]. One treatment-related death occurred $(0.84 \%)$ due to sepsis. An exposure-safety analysis was performed with pooled data $(n=513)$ from the IMvigor 210 and PCD $4989 \mathrm{~g}$ studies (NCT02108652 and NCT01375842) (Table 4) [18] for exposure metrics $\mathrm{AUC}_{21}, \mathrm{AUC}_{\mathrm{ss}}, C_{\max }$ and $C_{\text {min }}$. Safety endpoints were grade $3-5$ AEs, according to the Common Terminology Criteria for Adverse Events (CTCAE). However, no significant correlation between exposure and safety was identified. Additionally, an exposure-safety analysis was performed in 1007 individuals from the PCD4989g, BIRCH, FIR and POPLAR studies. The initial results demonstrated a positive relationship between $\mathrm{AUC}_{\mathrm{ss}}$ and both AEs of special interest (AESI) and AEs of grade 3 or higher; however, as in the efficacy analysis, these results are likely biased [19].

\subsection{Avelumab}

Avelumab (Bavencio ${ }^{\circledR}$ ) is a human $\mathrm{IgG} 1 \mathrm{mAb}$ targeting PD-L1. Avelumab is approved for the treatment of Merkel cell and urothelial carcinoma [21]. The recommended dose is $10 \mathrm{mg} / \mathrm{kg}$, administered every 3 weeks as a 60 -min intravenous infusion, based on the ability to sustain the target $C_{\text {ss, trough }}$ of $\geq 1 \mathrm{ug} / \mathrm{mL}$ associated with an ex vivo target occupancy $>90 \%$. Because of the unmodified IgG1 component, avelumab is capable of antibody-dependent cell cytotoxicity by binding to the Fcy receptor on natural killer (NK) cells.

\subsubsection{Pharmacokinetics}

The typical clearance of avelumab is $0.59 \mathrm{~L} /$ day (IIV 25\%), which is linear over the evaluated dose range of 1-20 mg/ $\mathrm{kg}$ [22]. Factors that affect variability in clearance are albumin concentration, body weight, sex and tumor burden. Avelumab exhibits time-varying clearance, i.e. change in clearance since the start of treatment, dependent on tumor type as well as response to therapy, with an average decline of $-3.1 \%$ over a period over 6 months [22]. Here, responders with Merkel cell carcinoma and other solid tumor types experience a larger decline in clearance (mean maximum reduction of $41.7 \%$ and $24.1 \%$, respectively) compared with those with other tumor types [22]. Post-baseline ADAs were detected in $4.1 \%$ of patients, and were associated with an average increase in clearance of $10-15 \%$ [22, 23]. The halflife of avelumab is estimated at 6 days (IIV 91.5\%), with steady state reached after 4-6 weeks [22]. The central and peripheral distribution volumes of avelumab are estimated at $2.83 \mathrm{~L}$ (IIV 18.3\%) and $1.7 \mathrm{~L}$ (IIV 1.05\%), respectively [22]. Factors that influence the volume of the central compartment are body weight and sex, but these are not considered clinically relevant. 
Table 4 Exposure-safety analyses

\begin{tabular}{|c|c|c|c|c|c|c|c|c|c|}
\hline $\begin{array}{l}\text { Generic } \\
\text { name }\end{array}$ & $\begin{array}{l}\text { No. of } \\
\text { patients }\end{array}$ & $\begin{array}{l}\text { Exposure } \\
\text { measure }\end{array}$ & Dose range & irAE & AESI & TEAE & $\begin{array}{l}\text { AE (grade } 3 \\
\text { or higher) }\end{array}$ & AE-D/DC & References \\
\hline Ipilimumab & 498 & $C_{\min , \mathrm{ss}}$ & $0.3-10 \mathrm{mg} / \mathrm{kg}$ & $\begin{array}{l}\text { Positive } \\
\text { relation- } \\
\text { ship }\end{array}$ & & & & & {$[15]$} \\
\hline \multirow[t]{2}{*}{$\begin{array}{l}\text { Atezoli- } \\
\text { zumab }\end{array}$} & 513 & $\begin{array}{l}\mathrm{AUC}_{21}, \\
\mathrm{AUC}_{\mathrm{ss}}, \\
C_{\max }, C_{\min }\end{array}$ & $\begin{array}{l}1-20 \mathrm{mg} / \\
\mathrm{kg} / 1200 \mathrm{mg}\end{array}$ & & $\begin{array}{l}\text { No relation- } \\
\text { ship }\end{array}$ & & $\begin{array}{l}\text { No relation- } \\
\text { ship }\end{array}$ & & [18] \\
\hline & 1007 & $\mathrm{AUC}_{\mathrm{ss}}$ & $\begin{array}{l}15 \mathrm{mg} / \\
\mathrm{kg} / 1200 \mathrm{mg}\end{array}$ & & $\begin{array}{l}\text { Positive } \\
\text { relation- } \\
\text { ship }\end{array}$ & & $\begin{array}{l}\text { Positive } \\
\text { relation- } \\
\text { ship }\end{array}$ & & [19] \\
\hline Avelumab & 1629 & $\begin{array}{l}\mathrm{AUC}_{\mathrm{ss}} \\
C_{\text {trough,first }}, \\
C_{\text {trough,ss }}\end{array}$ & $1-20 \mathrm{mg} / \mathrm{kg}$ & $\begin{array}{l}C_{\text {trough,ss }}: \\
\text { positive } \\
\text { relation- } \\
\text { ship }\end{array}$ & & $\begin{array}{l}\text { No relation- } \\
\text { ship }\end{array}$ & & & {$[22]$} \\
\hline Durvalumab & 1393 & $\begin{array}{c}C_{\max , 1}, \\
C_{\min , 2}, \\
C_{\min , \mathrm{ss}}\end{array}$ & $10 \mathrm{mg} / \mathrm{kg}$ & & $\begin{array}{l}\text { No relation- } \\
\text { ship }\end{array}$ & & $\begin{array}{l}\text { No relation- } \\
\text { ship }\end{array}$ & & [29] \\
\hline \multirow[t]{2}{*}{ Nivolumab } & 306 & Dose & $\begin{array}{l}0.1-10.0 \mathrm{mg} / \\
\mathrm{kg}\end{array}$ & & & & $\begin{array}{l}\text { No relation- } \\
\text { ship }\end{array}$ & $\begin{array}{l}\text { No relation- } \\
\text { ship }\end{array}$ & [33] \\
\hline & 336 & $C_{\mathrm{avg} 1}$ & $\begin{array}{l}0.1-10.0 \mathrm{mg} / \\
\mathrm{kg}\end{array}$ & & & & & $\begin{array}{l}\text { No relation- } \\
\text { ship }\end{array}$ & [34] \\
\hline \multirow[t]{2}{*}{$\begin{array}{l}\text { Pembroli- } \\
\text { zumab }\end{array}$} & 544 & $\begin{array}{l}\text { AUC } \\
\text { ss }-6 \text { weeks }\end{array}$ & $2-10 \mathrm{mg} / \mathrm{kg}$ & $\begin{array}{l}\text { No relation- } \\
\text { ship }\end{array}$ & & & & & [44] \\
\hline & & Dose & $2-10 \mathrm{mg} / \mathrm{kg}$ & $\begin{array}{l}\text { No relation- } \\
\text { ship }\end{array}$ & & & & & {$[44]$} \\
\hline
\end{tabular}

$A E$ adverse event, $A E-D / D C$ adverse events leading to drug discontinuation or death, $A E S I$ adverse events of special interest, irAE immunerelated adverse events, TEAE treatment-emergent adverse events, $C_{\text {trough,ss }}$ trough concentration at steady state, $C_{\text {min,ss }}$ minimum concentration at steady state, $A U C_{2 I}$ area under the concentration-time curve from time zero to $21 \mathrm{~h}, A U C_{S S}$ area under the concentration-time curve at steady state, $C_{\max }$ maximum concentration, $C_{\min }$ minimum concentration, $\mathrm{C}_{\text {trough,first }}$ trough plasma concentration after the first dose, $\mathrm{C}_{\text {max }, 1}$ maximum plasma concentration after the first dose, $\mathrm{C}_{\mathrm{min}, 2}$ minimum plasma concentration after the second dose, $\mathrm{C}_{\mathrm{avg} 1}$ time-averaged plasma concentration after the first dose

\subsubsection{Exposure-Efficacy Relationship}

Exposure-efficacy analysis was described for Merkel cell carcinoma (NCT02155647) (Table 3) [22]. Patients $(n=88)$ received avelumab at doses of $10 \mathrm{mg} / \mathrm{kg}$ once every 2 weeks. Clinical efficacy endpoints were progression-free survival (PFS), OS and ORR. ORR was defined as the best CTR or PTR response (RECIST v1.1).

Several significant exposure-efficacy relationships were identified. $\mathrm{AUC}_{\mathrm{ss}}$ was found to be associated with PFS and OS [22], while $C_{\text {trough,ss }}$ was identified as a predictor for PFS, ORR (saturating exposure-response curve at $28 \mu \mathrm{g} / \mathrm{mL}$ ) and OS. However, the potential interaction between tumor burden and clearance may have confounded the analysis with long-term steady-state PK metrics, such as $\mathrm{AUC}_{\mathrm{ss}}$ and $C_{\text {trough,ss }}$, since therapeutic response has been associated with a reduced clearance and higher drug exposure at later time points. In fact, evaluation of the relationship between the first-dose exposure metric $C_{\text {trough,first }}$ did not identify a correlation with PFS and OS, and a relatively weak relationship was detected with ORR [22].

\subsubsection{Exposure-Safety Relationship}

Five to $13 \%$ of individuals treated with avelumab developed grade 3-4 treatment-related AEs [24-26], including asthenia (2.3\%), aminotransferase elevation (1-2.3\%), blood cholesterol increase (1\%), creatine phosphokinase elevation (1-2.3\%), decreased appetite (2.3\%), increased lipase level (2\%), infusion-related reactions ( $2 \%$ ) and lymphopenia (2\%) [24-26]. There were no treatment-related deaths. An exposure-safety analysis for avelumab was performed on pooled data ( $n=1629$ patients) of the JAVELIN Solid Tumor, Solid Tumor JPN, and Merkel 200 studies (NCT01772004, NCT01943461, and NCT02155647) (Table 4). Doses evaluated ranged from 1 to $20 \mathrm{mg} / \mathrm{kg}$ [22]. The percentage of irAEs was used as an endpoint for clinical safety. Based on these criteria, a significant correlation was identified between $C_{\text {trough,ss }}$ and irAEs [22]. However, this might have been confounded by the interaction between tumor burden and clearance, which is further emphasized by the fact that no relationship was identified between $C_{\text {trough,first }}$ and irAEs [22]. 


\subsection{Durvalumab}

Durvalumab (Imfinzi ${ }^{\circledR}$ ) is a human $\operatorname{IgG} 1 \mathrm{mAb}$ against PD-L1, approved as a second-line therapy for the treatment of NSCLC and urothelial carcinoma (Table 1) [27]. Durvalumab is administered every 2 weeks as a 60 -min intravenous infusion at doses of $10 \mathrm{mg} / \mathrm{kg}$, leading to a $C_{\mathrm{ss} \text {, trough }}$ of $50 \mu \mathrm{g} / \mathrm{mL}$.

\subsubsection{Pharmacokinetics}

Durvalumab displays nonlinear clearance at doses below $3 \mathrm{mg} / \mathrm{kg}$, and linear clearance at doses of $3 \mathrm{mg} / \mathrm{kg}$ or above (Table 2) [28]. The typical clearance is $0.232 \mathrm{~L} /$ day (IIV $27 \%$ ) [28]. Factors that affect clearance are post-baseline ADA status, serum albumin concentration, body weight, cancer type, creatinine clearance, Eastern Cooperative Oncology Group performance status (ECOG PS), sex and soluble PD-L1. Among these, albumin concentration has the largest impact on clearance (-11\%) [28]. In addition, clearance was found to be time-dependent (maximum -16.9\%) over a period of 12 months [28]. The development of postbaseline ADAs was detected in 3.3-4.4\% of individuals and related to a maximum decrease in $C_{\text {trough,ss }}$ of $20 \%$ [28]. The average half-life of durvalumab is 21 days, with steady-state concentrations reached at approximately 16 weeks [28].

The central and peripheral volumes of distribution have been estimated at $3.51 \mathrm{~L}$ (IIV 20.9\%) and $3.42 \mathrm{~L}$ (IIV $33.6 \%$ ), respectively [28]. Body weight and sex were found to have a clinically significant effect on the volume of distribution.

\subsubsection{Exposure-Efficacy Relationship}

The exposure-efficacy relationship of durvalumab was evaluated for urothelial carcinoma $(n=91$ patients; NCT01693562) (Table 3) [29]. Clinical efficacy endpoints were best percentage change in target lesion and ORR (CTR or PTR, RECIST v1.1). No relationship was detected between $C_{\max }$ (cycle 1), $C_{\min }$ (cycle 2 ) and $C_{\min , s s}$, and efficacy.

\subsubsection{Exposure-Safety Relationship}

Safety concerns related to durvalumab therapy were assessed in 191 patients (NCT01693562) [30]. Grade 3-4 treatmentrelated AEs were reported for $6.8 \%$ of these participants [30]. Treatment-related death occurred in two individuals (1\%) due to autoimmune hepatitis and pneumonitis.

The exposure-safety analysis was based on two clinical trials $(n=1393)$ (NCT01693562 and NCT02087423) (Table 4) [29]. Participants received durvalumab at doses of $10 \mathrm{mg} / \mathrm{kg}$. AEs (grades 3-5) and AEs leading to discontinuation or death (AE-D/DC) were used as clinical safety endpoints. Based on these endpoints, an inverse relationship was found between certain exposure metrics and AEs (grades 3-5). However, because of the limited dataset, and the potential confounding with other risk factors such as albumin levels and ECOG status, these results were not considered conclusive [29].

\subsection{Nivolumab}

Nivolumab $\left(\right.$ Opdivo $^{\circledR}$ ) is a human IgG4 mAb against PD-1 (Table 1). The drug is approved for the treatment of melanoma, NSCLC, renal cell carcinoma, Hodgkin lymphoma, squamous cell cancer of the head and neck (SCCHN), urothelial carcinoma, MSI-H or dMMR colorectal cancer and hepatocellular carcinoma [31]. The recommended dose is either $3 \mathrm{mg} / \mathrm{kg}, 240 \mathrm{mg}$ or $480 \mathrm{mg}$, depending on tumor type and practical considerations, administered as a 30-min infusion once every 2 or 4 weeks (for the $480 \mathrm{mg}$ flat dose). The initial $3 \mathrm{mg} / \mathrm{kg}$ dose led to a $C_{\text {ss,trough }}$ that remained well above the ex vivo $>0.1 \mu \mathrm{g} / \mathrm{mL}$ target in phase I trials.

\subsubsection{Pharmacokinetics}

Nivolumab clearance is linear over the evaluated dose range of $0.3-10 \mathrm{mg} / \mathrm{kg}$ (Table 2), with an average of $0.360 \mathrm{~L} /$ day (normalized to a 80-kg body weight) [IIV 35\%] [32]. Clearance is time-dependent and decreases over time (maximum $-24.5 \%$ ) [32]. Patient-specific characteristics that influence clearance are baseline performance status, body weight, estimated glomerular filtration rate (eGFR), race and sex, which account for $30 \%$ of the variability in clearance [32]. The presence of post-baseline ADAs was found in $11.2 \%$ of individuals (26\% in combination with ipilimumab) and increased clearance by $14 \%$ on average $[31,32]$. The average half-life of nivolumab is 25 days (coefficient of variation $77.5 \%$ ), with steady-state reached by 12 weeks $[31,32]$. The nivolumab central and peripheral volumes of distribution are $3.63 \mathrm{~L}$ (IIV 35\%) and $2.78 \mathrm{~L}$ (IIV 35.1\%), respectively (normalized to a 80-kg, White female) [32]. Population PK analysis found that body weight and sex account for $21 \%$ of the variation in volume of the central compartment [32].

\subsubsection{Exposure-Efficacy Relationship}

Nivolumab dose-response and exposure-response analyses were performed in three distinct studies regarding melanoma $(n=107 ; n=221)$, NSCLC $(n=129)$ and renal cell carcinoma $(n=34)$ (NCT00730639 and NCT01721746) (Table 3) [33-35]. Participants received nivolumab at doses of 0.1 , $0.3,1.0,3.0$, or $10.0 \mathrm{mg} / \mathrm{kg}$. Clinical efficacy endpoints 
were PFS, ORR (RECIST v1.1.), OS, tumor progression rate (TPR) and tumor shrinkage rate (TSR).

For melanoma, there was no apparent relationship between ORR (at 52-56 days) and dose. However, there was a correlation between clearance and ORR across dose levels [33]. With respect to the exposure metrics, $C_{\text {min,ss }}$ was found to correlate with ORR, with a plateau at doses $\geq 1 \mathrm{mg} / \mathrm{kg}$. No relationship was established between the time-averaged concentration after the first dose $\left(C_{\text {avg } 1}\right)$ and ORR [34]. No apparent relationship was found between $C_{\text {avg1 }}$ and OS, but survival was negatively associated with clearance [34]. Lastly, $C_{\min , s s}$ was found to correlate with TPR, but not TSR, with a plateau at doses $\geq 3 \mathrm{mg} / \mathrm{kg}$ [33]. For NSCLC, ORR was higher at nivolumab doses of 3 and $10 \mathrm{mg} / \mathrm{kg}$ compared with the $1 \mathrm{mg} / \mathrm{kg}$ dose $(24.3 \%, 20.3 \%$ and 3\%, respectively) [33]. Furthermore, a correlation was observed between $C_{\text {min,ss }}$ and ORR (at 52-56 days), which saturates at doses $\geq 3 \mathrm{mg} / \mathrm{kg}$. Likewise, $C_{\text {min,ss }}$ was found to correlate to TPR, but not TSR, with a plateau at approximately $\geq 3 \mathrm{mg} / \mathrm{kg}$. For renal cell carcinoma, significant relationships between $C_{\text {min,ss }}$ and TSR (at 52-56 days), and average concentration at steady state $\left(C_{\mathrm{avg}, \mathrm{ss}}\right)$ and $\mathrm{OS}$, were initially established $[33,35]$. These correlations may have been overestimated due to the confounding element of timevarying clearance giving rise to increased exposures at later time points [35].

\subsubsection{Exposure-Safety Relationship}

Grade 3-4 treatment-related AEs were reported for $22.4-24 \%$ of patients receiving nivolumab [36, 37], with the most common being lymphopenia (2.8\%), diarrhea (1.9\%), abdominal pain (1.9\%), increased lipase (1\%), increased alanine aminotransferase (1\%), anemia (1\%), and fatigue $(1 \%)[36,37]$. Exposure-safety analysis was performed on data from 342 patients receiving nivolumab at doses ranging from 0.1 to $10 \mathrm{mg} / \mathrm{kg}$ (Table 4). AEs (grade 3-5) and AE-D/ DC were utilized as clinical safety endpoints. According to the analyses, dose is not a predictor for the occurrence of AEs (grade 3-5) [33]. In addition, time-averaged plasma concentration after the first dose $\left(C_{\mathrm{avg}, 1}\right)$ is not related to AE-D/DC [34].

\subsection{Pembrolizumab}

Pembrolizumab (Keytruda ${ }^{\circledR}$ ) is a fully humanized IgG4 $\mathrm{mAb}$ against the PD-1 antigen (Table 1). Pembrolizumab is approved for the treatment of melanoma, NSCLC, Hodgkin lymphoma, SCCHN, MSI-H or dMMR cancers, urothelial carcinoma and gastric cancer [38]. The recommended dose is either $2 \mathrm{mg} / \mathrm{kg}$ or $200 \mathrm{mg}$ once every 3 weeks, administered as a $30-\mathrm{min}$ intravenous infusion.

\subsubsection{Pharmacokinetics}

Pembrolizumab exhibits nonlinear clearance at doses below $0.3 \mathrm{mg} / \mathrm{kg}$, and linear clearance at doses of $0.3-10 \mathrm{mg} / \mathrm{kg}$ (Table 2) [39]. In addition, clearance displays time-dependent decline (average $20-30 \%$ ) over a period of 10 months, with a typical value of $0.168-0.249$ L/day (IIV 30.7-38\%) [39-41]. Factors that influence clearance are albumin and bilirubin concentration, cancer type, eGFR, ECOG-PS and sex, which together account for $32 \%$ of the variation [41]. The development of post-baseline ADAs was between 0.7 and 2.5\% among various trials [42]; however, the effect of ADAs on clearance was not evaluated [39-41]. The average half-life of pembrolizumab is in the range of 14-27.3 days, with steady state reached after approximately 18 weeks [39-41]. The typical central volume of distribution of pembrolizumab is estimated at a range of $2.88-3.48 \mathrm{~L}$ (IIV 19.6-21\%) [39-41]. Factors that influence this value are albumin levels, body weight, sex and prior ipilimumab therapy; however, none of these factors is considered clinically relevant.

\subsubsection{Exposure-Efficacy Relationship}

Pembrolizumab exposure-response analysis was performed for melanoma $(n=1366)$ and NSCLC $(n=496)$ [NCT01295827, NCT01704287 and NCT01866319) (Table 3) [43, 44]. The investigated doses were 2 and $10 \mathrm{mg} /$ $\mathrm{kg}[43,44]$. Efficacy was defined as a change from baseline in tumor size, of which a reduction of $30 \%$ or more was categorized as (complete) response according to RECIST v1.1. No significant relationship was established between pembrolizumab AUC over 6 weeks $\left(\mathrm{AUC}_{\mathrm{ss}-6 \text { weeks }}\right)$ and TSR or ORR, at 18 and 28 weeks $[43,44]$.

\subsubsection{Exposure-Safety Relationship}

Grade 3-4 treatment-related AEs occurred in $0-11 \%$ of the individuals administered pembrolizumab at $2 \mathrm{mg} / \mathrm{kg}$ doses [44-46], with the most common being colitis (3.6\%), pneumonitis $(3.6 \%)$, cardiorespiratory arrest $(1.8 \%)$, fatigue $(1 \%)$, generalized oedema (1\%) and myalgia (1\%). In addition, one treatment-related death $(2 \%)$ was reported, which may have been caused by prolonged prednisone administration after pembrolizumab-induced gastritis $[44,45]$.

The relationship between pembrolizumab exposure and safety was evaluated with data from 544 patients (NCT01295827) (Table 4) [44]. Patients received pembrolizumab at a dose of 2 or $10 \mathrm{mg} / \mathrm{kg}$. Safety was defined by the incidence of irAEs. No statistically significant correlation between pembrolizumab $\mathrm{AUC}_{\mathrm{ss}-6 \text { weeks }}$ and irAEs $(p=0.57)$ 
was found [44]. The incidence of irAEs was similar for the 2 and $10 \mathrm{mg} / \mathrm{kg}$ dose, although a longer treatment duration was found to be a risk factor for the development of irAEs [44].

\section{Discussion}

\subsection{Pharmacokinetics}

\subsubsection{Linear and Nonlinear Clearance}

Clearance of ICIs is governed by numerous physiological mechanisms, the predominant part of which is deemed to occur by nonspecific degradation within plasma and tissues (Fig. 2f) [47]. This aspecific route of degradation reduces the influence of age, hepatic impairment and renal failure on clearance, and thus minimizes the effect of these conditions on ICI exposure [21, 27, 31, 38, 48, 49].

Binding to the FcRn rescues mAbs from lysosomal degradation and is considered the driving mechanism behind the extended half-lives of ICIs ( $t_{1 / 2} 6-27$ days) (Fig. 2d) [47]. The reduced degradation of ICIs substantiates a prolonged tissue exposure and may therefore increase treatment effects without the necessity for frequent drug administration.

Target-mediated drug disposition (TMDD) provides an alternative route of elimination that consists of receptormediated endocytosis and degradation (Fig. 2g) [10, 47]. TMDD encompasses the phenomena in which high-affinity drug-target interactions affect the PK properties of a drug, and is considered the main process behind nonlinear distribution and elimination kinetics of mAbs. As TMDD depends on the number of ICI ligands, differences in target proteins can create differences in clearance patterns. A potential

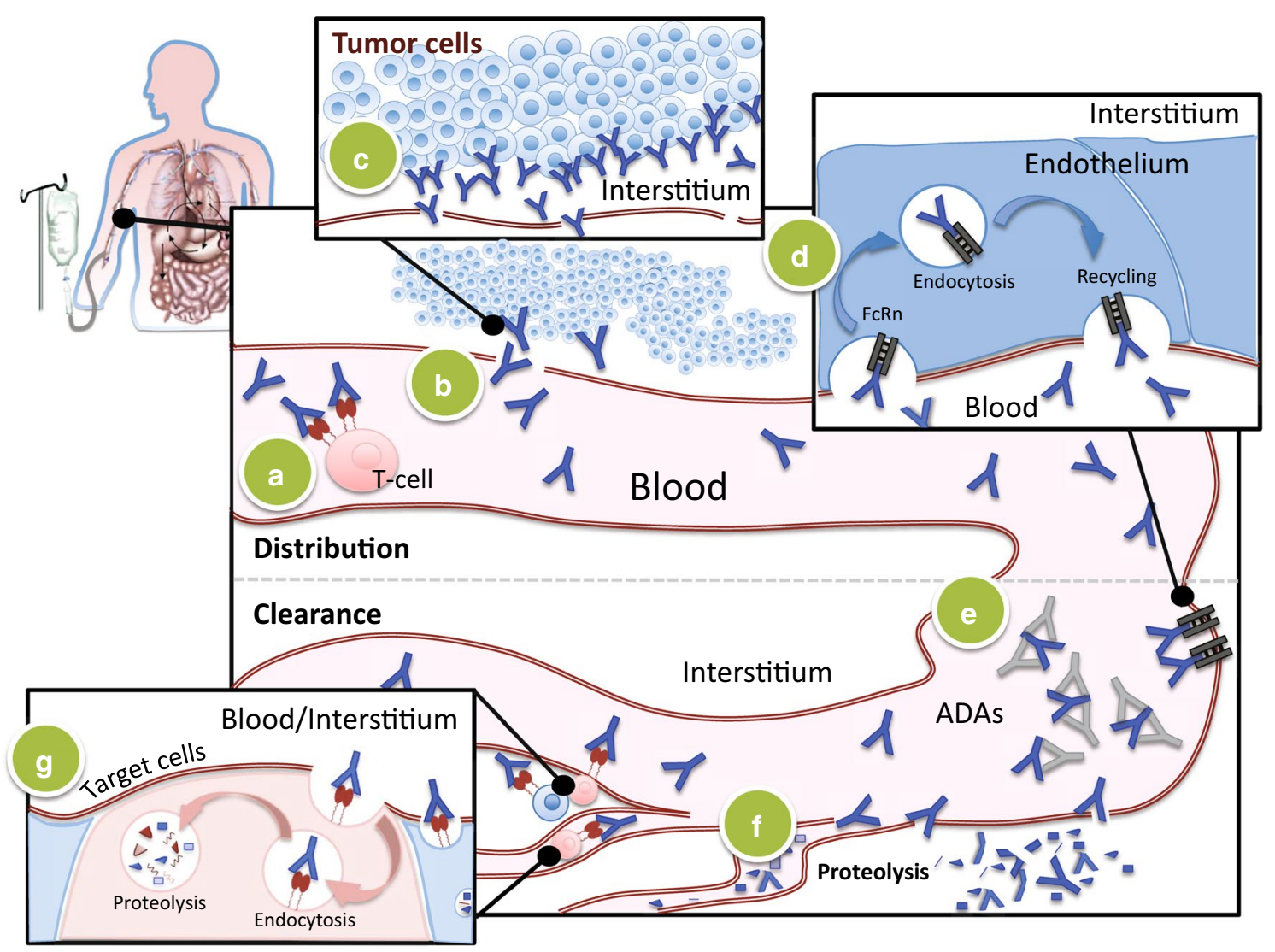

Fig. 2 Pharmacokinetics of ICIs. After intravenous administration, ICIs are distributed and metabolized by various routes. Extensive binding to target antigens in the (a) plasma or on (c) tissues, reduces the amount of free ICIs and increases the volume of distribution. (b) Transvascular movement of unbound ICIs is principally governed by means of convection, the magnitude of which is limited by factors such as organ perfusion and endothelial permeability. Within tissues, ICIs become distributed by means of diffusion and convection. (d) The FcRn is responsible for the transport of ICIs back into the vascu- lar system, preventing the intracellular degradation of these drugs and hence prolonging their half-life. (e) On the other hand, the generation of antibodies against ICIs increases clearance. (f) However, the dominant mechanism of ICI clearance remains through proteolytic catabolism, which occurs in both plasma and peripheral tissues. (g) Lastly, the high-affinity interaction between ICIs and surface receptors precipitates an additional clearance route, i.e. that of receptor-mediated endocytosis. ADAs antidrug antibodies, ICIs immune checkpoint inhibitors, FcRn neonatal Fc receptor 
example of this concept can be witnessed between the PD-1 receptor and PD-L1 ligand, wherein the latter target requires three to four times the amount of drug dosage (Table 1) because of differences in ligand expression. Saturation of TMDD occurs as the amount of mAbs exceeds the number of free targets, providing an explanation for nonlinear clearance of durvalumab and pembrolizumab at doses of 3 and $0.3 \mathrm{mg} / \mathrm{kg}$, respectively. The absence of nonlinear clearance among other ICIs can be a result of confined dose range evaluation, which may not transverse the point of saturation, or due to the minor influence of TMDD on these compounds.

Clearance can also occur through humoral and cell-mediated degradation pathways of the immune system (Fig. 2e). Formation of ADAs facilitates the uptake and endocytic degradation of ICIs, which increases clearance. It is believed that the development of such ADAs is largely determined by $\mathrm{mAb}$ structure, with increasing immunogenicity seen for human (-umabs, 0-10\%), humanized (-zumab, 0.4-18.5\%) and chimeric (-ximab, 1-17\%) antibodies in oncology [50]. In line with this assumption, the percentage of patients developing ADAs, as well as its impact on clearance, is considered limited in most ICIs, which are either human or humanized antibodies [13, 18, 29, 32]. Interestingly, the incidence of ADAs against nivolumab increased substantially (10-21.9\%) in patients receiving concomitant ipilimumab therapy, which might be a reason for the $24 \%$ increase in nivolumab clearance witnessed under combinational therapy [51]. This suggests that under combinational therapies, ADAs might have more significant consequences to the PK of ICIs in comparison to monotherapies. In addition, ADAs might influence treatment outcome outside the PK of their target compounds by, for instance, binding to their active moieties [50].

An additional route of endocytotic degradation might be facilitated by direct interaction between the Fc component of ICIs and $\mathrm{Fc} \gamma$ receptors (Fc $\gamma \mathrm{Rs}$ ) on phagocytic cells of the immune system [47]. Recent preclinical data have shown that $\mathrm{Fc}$ isotype is an important determinant of $\mathrm{Fc} \gamma \mathrm{R}$ mediated interaction, wherein the IgG1 subtype displays high affinity for FcyR in comparison to the IgG4 subtype [52]. However, with the exception of avelumab [22], the IgG1 Fc components of PD-L1 inhibitors have been tailored to be less vulnerable to this specific interaction. Absence of this modification might be the reason that avelumab displays a relatively short half-life when compared with other ICIs [53]. However, there is no substantial evidence to support the notion that FcyR has an effect on the PK of mAbs [54].

\subsubsection{Time-Varying Clearance}

With the exception of ipilimumab, ICIs exhibit time-varying clearance, i.e. a change in clearance over time after the start of treatment. This phenomenon has largely been attributed to disease status: clearance decreases when tumor burden declines; however, uncertainty exists as to what mechanism drives this interaction $[32,35,40]$. Cachexia, which marks a general state of catabolism, is often seen in patients with more invasive tumors. The condition is known to cause rapid degradation of proteins, including, potentially, ICIs, and ameliorates with improved disease status [55]. Durvalumab [28] and pembrolizumab [56] represent two very recent examples of time-varying clearance attributed to protein catabolism. However, cachexia-induced catabolism does not clarify the lack of time-varying clearance seen for ipilimumab.

More fitting is the explanation of TMDD, which hinges on the presence of cell surface targets. The availability of these targets, regardless of whether expressed on tumor cells or T cells reacting to tumor cells, is expected to correlate to disease status [57-60]. Improvement in tumor burden reduces the amount of available surface targets and hence limits the capacity of target-mediated degradation of ICIs. Ipilimumab is unique in the sense that the compound affects $\mathrm{T}$ cells within the priming phase, prior to extensive proliferation, while anti-PD-1 compounds target these cells after proliferation (Fig. 1) [61, 62]. Moreover, ipilimumab targets a ligand that is primarily restricted to activated $\mathrm{T}$ cells, whereas PD-1 is expressed on a wide range of immune cells [62]. The absence of time variation in ipilimumab might thus be caused by the relatively low amount of target cells in comparison to other ICIs. In support of this supposition, no time-varying clearance has also been established for tremelimumab, another mAb against CTLA-4 that is currently undergoing human trials for various cancers [63].

\subsubsection{Distribution}

ICIs are largely confined to the vascular compartment, as reflected by their limited volumes of distribution $\left(V_{\mathrm{ss}} \approx 4-7 \mathrm{~L}\right)$. Gradual distribution to the periphery ( $Q=0.38-1.2 \mathrm{~L} /$ day) is presumptively capacitated by the process of convection (Fig. 2b), which is considered the dominant mechanism behind the distribution of mAbs from the blood to the interstitial compartment, and the occurrence of TMDD [10, 47]. Factors that influence target availability, such as cancer type and disease burden, can thus shape the PK of these compounds (Fig. 2a, c). Although this manifestation is largely theoretical at this point, the distribution of avelumab is found to differ among cancer types [22].

\subsubsection{Therapeutic Drug Monitoring}

Therapeutic drug monitoring (TDM) conveys the surveillance of drug exposure and is advantageous for compounds that satisfy certain criteria. Among these criteria are (1) large IIV in exposure, with relatively low intraindividual 
variation; (2) significant exposure-response relationship; (3) a narrow therapeutic window; and (4) availability of a validated bioanalytical assay [64].

Most PK studies performed during clinical trials are conducted in drastically selected patients. Consequently, the range of plasma exposures of ICIs in real-life patients treated with standard dosing may exceed that observed from registration trials and may therefore be underestimated. Estimates of residual error reported for the six ICIs reviewed ranged from 16 to $27 \%$ [13, 18, 22, 29, 32, 41], indicating that the magnitude of intraindividual variability will unlikely represent a limitation in TDM. A better understanding and characterization of time-varying PK parameters will improve the outcome of TDM programs applied to ICIs.

Although some concentration-efficacy relationships have been identified, as discussed in this review, currently insufficient clinical evidence generally exists to define specific concentration or exposure targets. Ex vivo or in vitro concentration targets might be problematic to use given the complexity of translating these concentration targets to an in vivo context. Based on current data, TDM strategies are particularly relevant for ipilimumab, which is already characterized by clear exposure-efficacy and exposure-safety relationships. The use of weight-based dosing has proven insufficient as body weight only accounts for a subset of IIV in exposure (Table 2). As a consequence, TDM can thus be of particular importance for ipilimumab in order to homogenize plasma levels between individuals and hence optimize clinical outcome by means of dose and/or schedule alternations. A potential target concentration might be at a $C_{\text {trough,ss }}$ between 57 and $155 \mu \mathrm{g} / \mathrm{mL}$ [13], but requires further confirmation.

Although little to no dose-limiting toxicities have been reported for ICIs, the establishment of a therapeutic window within the efficacy range can avert dispensable expenses. A potential candidate for this application is nivolumab, for which the exposure-response curve reaches saturation below marketed doses [33]. This saturation theoretically permits dose minimization, or prolongation of the dose interval, thus potentiating the role of TDM in cost reduction [65]. Future work should focus on determining if the measurement of plasma levels is truly cost effective, as in silico studies suggest [9]. Importantly, according to phase I trials, nivolumab dosing as low as $0.1 \mathrm{mg} / \mathrm{kg}$, leading to simulated trough concentrations of $2.5 \mu \mathrm{g} / \mathrm{mL}$, was sufficient to ensure optimal PD-1 inhibition [1, 2]. However, in a pilot study in NSCLC patients, it was shown that a target trough level of $>34 \mu \mathrm{g} /$ $\mathrm{mL}$ was associated with a higher response rate [66]. This discrepancy could come from some flaws in the very way target engagement was initially measured in circulating $\mathrm{T}$ lymphocytes, and not at the tumor level, during early phase I studies (see the Exposure-Efficacy Relationships paragraph below). Durvalumab is an anti-PD-L1 ICI for which a minimum concentration of $50 \mu \mathrm{g} / \mathrm{mL}$ has been proposed to saturate both soluble and membrane-bound PD-L1 in serum [28]. However no clinical data have yet been made available to support this value as being a cut-off associated with better clinical outcome with durvalumab.

\subsubsection{Serum Assays for ICls}

One of the prerequisites for TDM is access to a validated and standardized bioanalytical assay [64]. Measuring the functionally active ICI concentration represents a challenge since mAbs in serum or plasma can be in complex with either the target antigen or ADAs. Serum measurements of ICIs have to date been largely performed by means of electrochemiluminescence immunoassays (ECLIAs) or enzymelinked immunosorbent assays (ELISAs) [13, 18, 22, 29, 32, 39-41]. ELISAs only quantify unbound ICIs and do not meet the requirements for future routine application. For mAbs, the division between unbound and target-bound drug can strongly depend on plasma concentration, resulting in dosedependent distribution [67]. Measurement of both values can therefore ameliorate current estimations of distribution kinetics. Recent advances in proteomics research has shown that liquid chromatography-tandem mass spectrometry (LC-MS/MS) methods are capable of analyzing peptide and protein in biological matrix without compromising the exceptional selectivity and specificity that are a feature of absolute chromatographic quantification. A major advantage is the absence of interference from ADAs and target proteins, enabling an accurate assessment of the total drug concentration in samples [68].

\subsection{Exposure-Efficacy Relationships}

\subsubsection{Target Engagement}

Whereas ICIs were originally considered to act in a purely antagonistic manner, more recent advances have demonstrated that several compounds might directly give rise to cytotoxic reactions [69]. Antibody-dependent cellular cytotoxicity (ADCC) and complement-dependent cytotoxicity (CDC) arise by the interaction between the $\mathrm{Fc}$ region of ICIs and components of the immune system, which might cause depletion of target cells [52]. As discussed earlier, the capacity to evoke such an immune response is highly dependent on the isotype involved, where members of the $\mathrm{IgG1}$ group are able to induce ADCC and CDC [52,69].

Within such context, IgG1 ICIs serve as "classical deleters' of intratumoral regulatory $\mathrm{T}$ cells (Treg cells) because of the capacity to induce cellular and humoral cytotoxicity, while IgG4 ICIs function as true receptor blockers that antagonize the inhibition of T cells [69]. In clinical practice, unmodified IgG1 compounds give rise 
to a higher degree of infusion-related reactions, as seen in avelumab [70]. With respect to the antitumor effect, avelumab has demonstrated augmented tumor killing through ADCC in vitro and ex vivo [71]; however, the degree of clinical benefit that might be related to this mechanism of action has not been clearly shown in clinical studies.

Next to avelumab, anti-CLTA-4 compounds might be responsible for ADCC of Treg cells in the tumor microenvironment [72]. This mechanism of action was also hypothesized to be the reason for the steep dose-response relationship that is seen in ipilimumab ( $\operatorname{IgG} 1)$ [73]. In murine studies, ipilimumab was found to induce ADCC of Treg cells by both NK cells and myeloid cells, whereas for tremelimumab, this was solely by means of the myeloid lineages [74]. Despite this difference on a cellular level, clinical efficacy demonstrates no discrepancies and OS appears similar between compounds [75]. In addition, Treg depletion did not occur in the tumor microenvironments of patients treated with ipilimumab or tremelimumab [76], indicating that on a clinical level, ADCC might not be as relevant as preclinical studies suggest.

Another important issue related to target engagement relates to the relative contribution of PD-L2. As previously explained, PD-1 becomes activated by binding to either PD-L1 or PD-L2 (Fig. 1). Blockage of the PD-1 receptor is therefore considered capable of antagonizing the interaction with both ligands, while PD-L1 blockade allows binding of PD-L2 to PD-1. Based on this assumption, it seems reasonable to believe that $\mathrm{PD}-1$ blockage generates more antitumor and autoimmune responses in comparison to PD-L1. However, in patients with NSCLC, the efficacy and toxicity profiles of PD-1 and PD-L1 therapies appeared to be similar [77]. Similarly in other cancers, the expression of PD-L2 in the tumor microenvironment was not related to treatment response to PD-1 blockage, independently of PD-L1 [78]. For SCCHN only, the expression of PD-L2 has been related to treatment response with PD-1, suggesting that blockage of both PD-L1 and PD-L2 might support additional clinical benefit for this group of patients.
With respect to PD-1 blockers, PD-1 occupancy of peripheral cells has been repeatedly evaluated as part of early phase I trials with nivolumab [1, 2]. Rather remarkably, target engagement was found to be independent of dosing over a $0.1-10 \mathrm{mg} / \mathrm{kg}$ range, i.e. $60-70 \%$ of receptor occupancy. In addition, single dosing achieved sustained inhibition of the target over weeks because of the pure antagonist nature of anti-PD-1 drugs. Such data strongly suggest that PK/PD relationships are 'flat' with this kind of ICI because the PD endpoint does not seem to be related to dosing.

\subsubsection{Overall Survival}

OS provides the most valid information in the interest of dose optimization, and to date has been utilized for three ICI exposure-response analyses. For several of these compounds, decreasing time-dependent clearance might create the deceitful semblance that higher drug exposure is the cause, rather than the consequence, of greater efficacy [22, 35]. As previously discussed, time-variant clearance can potentially be caused by both disease-specific factors (i.e. disease burden, tumor type) and patient characteristics (i.e. cachectic status). This risk for confounding urges for adaptation of early-phase exposure metrics, as opposed to steadystate exposure metrics, to isolate the influence of exposure to OS in compounds with time-dependent clearance. For the two compounds in which this holds true, avelumab and nivolumab, early exposure metrics are not predictive of OS. The absence of an exposure-OS relationship suggests that dose reduction may be warranted in these compounds. On the other hand, the correlation between exposure and OS indicates that individualized dose escalations might be justified for ipilimumab [15].

\subsubsection{Surrogate Clinical Endpoints}

Since OS data are not available for several ICIs, exposure-response analyses have been largely based on early clinical endpoints, such as PFS and ORR [79], which may not correlate well to OS (Table 5) [80-83] due to the PD

Table 5 Summary of studies that investigated the correlation between OS and surrogate endpoints

\begin{tabular}{lllll}
\hline Cancer type & Investigated therapies & Correlation ORR/OS & Correlation PFS/OS & References \\
\hline All & Anti-PD-1/PD-L1 & $R^{2}=0.066(p=0.251)$ & $R^{2}=0.432(p=0.032)$ & {$[80]$} \\
Melanoma & ICIs & $R^{2}=0.028(p=0.279)$ & $R^{2}=0.192(p=0.154)$ & {$[80]$} \\
Nonsmall cell lung cancer & ICIs & $R=0.452(p=0.141)$ & $R=0.473(p=0.120)$ \\
Renal cell carcinoma & ICIs and other drugs & $89-96 \%$ for RD, 81-91\% for & - & {$[81]$} \\
& & SD, and 50-70\% for PD & & {$[82]$} \\
Urothelial carcinoma & ICIs and other anticancer drugs & $R=0.37(p=0.30)$ & - & {$[83]$} \\
\hline
\end{tabular}

$O R R$ overall response rate, $O S$ overall survival, $P D$ progressive disease, $P F S$ progression-free survival, $R D$ responders (complete/partial response), $S D$ stable disease, $P D-1$ programmed death $1, P D-L 1$ programmed death-ligand $1, I C I s$ immune checkpoint inhibitors 
mechanism of action, which is not aimed directly against tumor cells but rather eventuates by means of the immune system [84]. This indirect effect gives rise to unusual response kinetics, such as delayed clinical response, mixed responses preceding general response, and even tumor progression prior to response [85]. Since both ORR and PFS lack the capacity to perceive tumor lesion progression as an early marker of tumor regression, there is a need for an alternative endpoint to predict OS.

A set of irRCs have been designated to comprehensively characterize the response kinetics of immune-oncologic drugs [86]. Compared with RECIST, irRCs account for the delayed response that is seen with ICIs, and classify the initial development of novel lesions under tumor burden (electronic supplementary Table S1). Among studies that have investigated ICIs, correlation between exposure and tumor response appears more significant when evaluated according to irRCs (4.3-25.6\%) compared with ORR (0.6-11.6\%) [15]. In addition, the criteria bear an obvious advantage over OS by providing an instrument for early efficacy assessments [87]. These observations underline the potential value of irRCs as an early clinical endpoint tool to characterize ICI efficacy. However, in order to determine the best surrogate endpoint with certainty, additional studies need to verify the correlation between irRCs, ORR and PFS to OS, for each ICI and cancer type individually.

\subsubsection{Biomarkers}

Despite their impressive clinical outcomes, response rates for all ICIs administered as monotherapy fall below 50\% regardless of tumor type. The current challenge either in drug development and clinical patient care, is first to identify as early as possible non-responders, and then select the best candidates in a drug combination strategy including co-administering different ICIs, including chemotherapeutic and targeted agents, and others immune-modulators as vaccines and toll-like receptors agonists.

Studies with melanoma, NSCLC, renal cancer, SCCHN, and urothelial carcinoma found that intratumoral PD-L1 expression prior to treatment provides a higher likelihood for treatment response, even though absence of PD-L1 expression does not rule out treatment response in all patients [88]. At the moment, a PD-L1 immunohistochemistry (IHC) test accompanies patient selection for atezolizumab and pembrolizumab treatment for locally advanced or metastatic urothelial carcinoma [38, 49]. Similarly, a PD-L1 IHC (28-8 pharmDx) test was approved as a complementary diagnostic test of nivolumab for patients with NSLCL and melanoma [88]. In May 2017, the US FDA approved Roche's VENTANA PD-L1 (SP263) assay as a diagnostic for the qualitative detection of PD-L1 expression in patients with locally advanced or metastatic urothelial carcinoma who are being considered for treatment with durvalumab [89]. Nevertheless, the application of PD-L1 testing contains many pitfalls, including deviations in PD-L1 expression in time and location, concomitant PD-L1 expression in the tumor cytoplasm or microenvironment, and inaccuracies of needle biopsies and histological strategies, not to mention discrepancies between diagnostic kits [88].

An alternative biomarker for ICI efficacy is total mutational load, which relies on the notion that the number of mutations correlates to tumor immunogenicity and therefore therapeutic response [88]. However, since not all mutations give rise to immune-stimulating neoepitopes, this approach requires algorithms that can predict the immunogenicity of mutational profiles. Currently, microsatellite instability (MSI) status in colorectal patients has been the most consistent predictive biomarker for treatment efficacy with antiPD1, but only relates to $4 \%$ of patients [90].

In addition, quantification of absolute rise in lymphocyte count in peripheral blood may act as a biomarker for antiCLTA-4 therapies [88]. Future studies should further explore this biomarker and determine which subset of lymphocytes hold the most predictive potential.

All these studies have addressed the issue of receptor occupancy in circulating lymphocytes collected from peripheral blood mononuclear cells, and no data on PD-1 inhibition at the tumor level has yet been made available. Therefore, it is speculated that the drug level achieving a correct target engagement in the vascular space will be sufficient to inhibit the target in the tumor microenvironment. The long-lasting inhibition of PD-1 and the fact that circulating T lymphocytes are likely to infiltrate the tumor next supports this hypothesis; however, with respect to the poor tissue/blood ratio (i.e. 0.5-0.1) of most therapeutic mAbs [14], to what extent desired exposure level in the bloodstream will lead to correct PD1 inhibition at the tumor level remains to be fully elucidated, making the monitoring of receptor occupancy in circulating lymphocytes, and not in tumor lymphocytes, a speculative PD endpoint .

\subsubsection{Biomarker Exposure-Response Relationships}

The use of PKPD modeling of biomarker exposure-response (biomarker)-clinical outcome relationships has developed as an important tool in drug development; however, for ICIs, these approaches may need to be at least reconsidered. The study regarding the role of biomarkers reflecting tumor microenvironment-related mechanisms, as is the case for myeloid suppressor cells, is warranted and is the object of enormous pre- and clinical research activity. If a low immunogenic (cold) tumor needs to be converted to a warm, hot tumor sensitive to ICIs with the help of immune-modulator therapies, the playing field goes beyond the T-cell perimeter 
and expands to the full cancer immunity cycle, considering presentation, recognition, activation, and expansion as key factors for an efficacious tumor response [94].

Systemic drug exposure is mostly used to study variability in the PK of any type of drug, however more and more physiological-based PK (PBPK) is being used to understand PK variability and project drug concentrations in the tissues of interest. Recent works suggest the need to study drug kinetics in the tumor, potentially to optimize drug schedules [95-97]. Several PBPK models have been established for different mAbs and, it is expected, applications to different ICIs in the near future.

\subsubsection{Dose Optimization}

Approved dosing regimens may not necessarily be optimal, and bedside practice can sometimes lead to alternate, more efficacious and/or better tolerated ways to administer drugs. For instance, it took nearly one decade to deconstruct sunitinib scheduling and to establish a new paradigm [98]. With ICIs, dose- or exposure-response analyses have been performed, however several studies are limited by narrow dose ranges, suboptimal endpoints and issues of confounding factors (Tables 3, 4). Based on these limitations, only minimal inferences can be made with respect to dose adjustment [99].

The flat relationship between nivolumab exposure and OS in melanoma suggests that current exposure values are not essential for drug efficacy, and dose reduction is permitted for this compound [34]. The same applies for the adaptation of nivolumab for the treatment of renal cell carcinoma [35].

For ipilimumab, dose adjustment can be considered for two separate reasons. In the first place, the correlation between exposure and efficacy advocates for adaptive dosing strategies in order to increase OS. Furthermore, the correlation underlines the necessity to reduce the current betweenpatient variability in exposure (Table 2). For now, ipilimumab is administered based on body weight as this significantly affects both clearance and volume of distribution [13]. However, body weight merely accounts for a subset of the between-patient variability ( $24 \%$ and $52 \%$, respectively) and additional measure may be required. TDM provides a means to homogenize exposure across individuals at a value that is expected to produce the best clinical efficacy outcomes.

Finally, the rational identification and optimization of combinations of ICIs with chemotherapeutic agents or other ICIs is currently or great interest [91, 92]. Here, the use of systems pharmacology modeling approaches in this context can be highly relevant to support the selection of rational combination therapies [93].

\subsection{Exposure-Safety Relationships}

Treatment with ICIs gives rise to a novel spectrum of AEs, the irAEs, that emanate through erroneous activation of the immune response and can be considered an undesirable result of their PD mechanism of action [100]. Several of these irAEs include dermatological, gastrointestinal and a number of endocrine inflammatory responses, which differ from 'traditional' AEs by their nature, but also by their delayed onset, fluctuating course and unclear relationship to drug exposure. Although the occurrence of severe irAEs is rare, especially in terms of fatalities, these AEs can tremendously affect quality of life and tarnish treatment continuation [100]. As a consequence, potential correlations to drug exposure should become established and be considered during the process of drug optimization.

The unique kinetics of safety in ICI therapy demand an adapted evaluation process of AEs [99]. Safety parameters such as maximum tolerated dose and dose-limiting toxicities are not relevant for ICIs, or, conversely, may appear meaningful outside the typical 4-week observation period.

Exposure-AE relationships have been described for ipilimumab and pave the way for more accurate and tailored doses for this compound [15]. Given the large betweenpatient variability in exposure of ipilimumab, dose adjustment may be beneficial. Approaches to optimize dosing of these compounds have been discussed in previous paragraphs.

Because PD-1 and PD-L1 govern immune resistance further down the inflammatory cascade, PD-1/PD-L1 inhibitors give rise to relatively less irAEs than CTLA-4 blockers [101]. In fact, the CTLA-4 blocker ipilimumab was associated with both an increased and broader range of irAEs compared with PD-1 antagonists [101, 102]. Out of the spectrum of irAEs, colitis and hypophytis occur more frequently under the CTLA-4 blocker ipilimumab, whereas pneumonitis and thyroiditis appear more often under PD-1 blockers. Although the reason for these discrepancies remains obscure, it has been hypothesized to reside in the different mechanism of action, which can ensue through cytokines, T cells, complement factors and endogenous antibodies [102].

Regardless of the mechanism of action, differences in clinical toxicity might represent a base for drug selection in those cases where efficacy appears similar. For ipilimumab, human trials have been performed together with nivolumab and pembrolizumab to compare clinical safety and efficacy profiles of these compounds in melanoma [103, 104]. Strikingly, both trials found that PD-1 blockers prolonged PFS and induced less AEs compared with ipilimumab. Further comparison of the PD-1 blockers suggests that pembrolizumab induces more irAEs compared with nivolumab [101]; however, the interpretation here should be cautious as the comparison was made between studies.

Because of the limited availability of comparative trials involving PD-L1 blockers, the relative benefit and disadvantages of these ICIs remains obscure. However, it is possible that PD-L1 blockers are associated with relatively less 
irAEs due to PD-L2 exclusion. In patients with NSCLC, PD-1 blockers provided similar ORR and OS compared with atezolizumab; however, the degree of irAEs was lower for the latter [77]. For urothelial carcinoma, the differences between PD-1 and PD-L1 blockers appears more difficult to define [105].

\subsection{Pharmacoeconomic Considerations}

Since the year 2000, the costs of cancer therapy have more than doubled and, with the prospective approval of novel (immuno)therapies for a myriad of cancer types, these costs are expected to rise even further [106]. Among many factors, such as therapeutic costs and cancer prevalence, dosing regimen is one of the driving forces behind these developments. Along these lines, the connections between dose, exposure, and clinical outcome can be used as a base to optimize the benefit-cost balance and avoid unnecessary expenses.

Most exposure-response analyses do not currently provide sufficient information to pinpoint candidates for dose reduction. Lower doses might be warranted for nivolumab in the treatment of melanoma and renal cell carcinoma, for which the exposure-efficacy curves saturate at doses between 1 and $3 \mathrm{mg} / \mathrm{kg}$ (Table 3). Future efforts should elucidate whether dose reduction is permitted for additional compounds. This is of particular relevance for atezolizumab and durvalumab, for which no exposure-response relationships were found in an analysis, but wherein only a single dose was evaluated. Moreover, as most ICIs display progressive decrease in clearance, the possibility for dose reduction in relation to this phenomenon should be explored.

An alternative approach to cost reduction is that of fixed dosing, as discussed in a recent review [107]. Fixed doses are of particular interest for compounds with flat exposure-response relationships, for which variations in exposure do not affect clinical outcome, as well as for compounds whose PK are not significantly affected by body weight. Despite the fact that all ICIs meet these prerequisites, with the exception of ipilimumab, only about half of the recommended dosing regimens are based on fixed doses (Table 1). In support of this theory, comparison of weight-based to fixed doses for avelumab, nivolumab and pembrolizumab demonstrate that exposure, safety and efficacy are comparable between these dosing regimens [22, 51, 108]. Based on these findings, wider application of fixed doses is justified and should become pursued in the near future.

\section{Conclusion}

Cancer immunotherapy with ICIs is still associated with suboptimal efficacy, as $<50 \%$ of patients show a significant increase in survival in solid tumors. Among the possible strategies to improve clinical outcome while sparing public expense, the optimization of exposure levels as a means to predict efficacy or to reduce toxicities has not yet been fully considered with ICIs. For now, monitoring $C_{\text {ss,trough }}$ appears a reasonable option that, given the time-dependent clearance of some ICIs, should be repeated over multiple cycles to ensure dose adjustments to possible changes in exposure. Comprehensive studies are warranted to determine to what extent TDM with adaptive dosing strategies could help improve clinical outcome with immunotherapy. With respect to exposure-response analysis, early exposure parameters such as $C_{\text {trough,first }}$ should be used in order to avert confounding related to time-variant clearance. The PK properties of ICIs are determined by a wide variety of factors, including TMDD and physicochemical-based constraint to the vascular compartment. ICIs have a unique and challenging safety profile, but an unconfounded exposure-response relationship has only been shown for ipilimumab. The use of surrogate clinical endpoints for ICIs to perform exposure-efficacy analyses is a concern because of their lack of predictive value for OS. Novel immune activation biomarkers would be of relevance to further optimize treatment and trial designs with respect to the PK and PD of ICIs. Finally, to enable PK and PD biomarkerguided dose individualization and optimization of ICIs, the use of population PKPD modeling and simulation to support rationalized individualization, including special patient populations, will be crucial to enable selection of dose regimens that optimize efficacy, toxicity and cost [109-113].

Acknowledgements Johan G. Coen van Hasselt is supported by a Marie Curie individual fellowship (Project ID 661588).

\section{Compliance with Ethical Standards}

Conflict of interest Maddalena Centanni, Dirk Jan A. R. Moes, Iñaki F. Trocóniz, Joseph Ciccolini, and Johan G. Coen van Hasselt have no conflicts of interest to declare related to the contents of this manuscript.

Funding No funding was received for the preparation of this manuscript.

Open Access This article is distributed under the terms of the Creative Commons Attribution-NonCommercial 4.0 International License (http://creativecommons.org/licenses/by-nc/4.0/), which permits any noncommercial use, distribution, and reproduction in any medium, provided you give appropriate credit to the original author(s) and the source, provide a link to the Creative Commons license, and indicate if changes were made.

\section{References}

1. Brahmer JR, Tykodi SS, Chow LQM, Hwu W-J, Topalian SL, Hwu P, et al. Safety and activity of anti-PD-L1 
antibody in patients with advanced cancer. N Engl J Med. 2012;366(26):2455-65.

2. Topalian SL, Hodi FS, Brahmer JR, Gettinger SN, Smith DC, McDermott DF, et al. Safety, activity, and immune correlates of anti-PD-1 antibody in cancer. N Engl J Med. 2012;366(26):2443-54.

3. Caroline R, Luc T, Igor B, Steven O, Jeffrey W, Claus G, et al. Ipilimumab plus dacarbazine for previously untreated metastatic melanoma. N Engl J Med. 2011;364:2517-26.

4. Hodi FS, O'Day SJ, McDermott DF, Weber RW, Sosman JA, Haanen JB, et al. Improved survival with ipilimumab in patients with metastatic melanoma. $\mathrm{N}$ Engl $\mathrm{J}$ Med. 2010;363(8):711-23.

5. Pardoll DM. The blockade of immune checkpoints in cancer immunotherapy. Nat Rev Cancer. 2012;12:252-64.

6. Jezeršek Novaković B. Checkpoint inhibitors in Hodgkin's lymphoma. Eur J Haematol. 2016;96:335-43.

7. Sharma P, Allison JP. The future of immune checkpoint therapy. Science. 2015;348:56-61.

8. Marin-Acevedo JA, Dholaria B, Soyano AE, Knutson KL, Chumsri S, Lou Y. Next generation of immune checkpoint therapy in cancer: new developments and challenges. J Hematol Oncol. 2018;11:39.

9. Ogungbenro K, Patel A, Duncombe R, Nuttall R, Clark J, Lorigan $P$. Dose rationalization of pembrolizumab and nivolumab using pharmacokinetic modeling and simulation and cost analysis. Clin Pharmacol Ther. 2018;103(4):582-90.

10. Wang W, Wang EQ, Balthasar JP. Monoclonal antibody pharmacokinetics and pharmacodynamics. Clin Pharmacol Ther. 2008;84:548-58.

11. Pointreau Y, Azzopardi N, Ternant D, Calais G, Paintaud G. Cetuximab pharmacokinetics influences overall survival in patients with head and neck cancer. Ther Drug Monit. 2016;38(5):567-72.

12. Caulet M, Lecomte T, Bouché O, Rollin J, Gouilleux-Gruart V, Azzopardi N, et al. Bevacizumab pharmacokinetics influence overall and progression-free survival in metastatic colorectal cancer patients. Clin Pharmacokinet. 2016;55:1381-94.

13. Feng Y, Masson E, Dai D, Parker SM, Berman D, Roy A. Modelbased clinical pharmacology profiling of ipilimumab in patients with advanced melanoma. Br J Clin Pharmacol. 2014;78:106-17.

14. Ryman JT, Meibohm B. Pharmacokinetics of monoclonal antibodies. CPT pharmacomet Syst Pharmacol. 2017;6:576-88.

15. Feng Y, Roy A, Masson E, Chen T, Humphrey R, Weber JS. Exposure-response relationships of the efficacy and safety of ipilimumab in patients with advanced melanoma. Clin Cancer Res. 2013;19(14):3977-87.

16. Ibrahim RA, Berman DM, DePril V, Humphrey RW, Chen T, Messina M, et al. Ipilimumab safety profile: summary of findings from completed trials in advanced melanoma. J Clin Oncol. 2011;29:8583.

17. Bertrand A, Kostine M, Barnetche T, Truchetet M-E, Schaeverbeke $\mathrm{T}$. Immune related adverse events associated with antiCTLA-4 antibodies: systematic review and meta-analysis. BMC Med. 2015;13:211.

18. Stroh M, Winter H, Marchand M, Claret L, Eppler S, Ruppel $\mathrm{J}$, et al. Clinical pharmacokinetics and pharmacodynamics of atezolizumab in metastatic urothelial carcinoma. Clin Pharmacol Ther. 2017;102:305-12.

19. Center for Drug Evaluation and Research [CDER], US FDA. Clinical pharmacology and biopharmaceutics review(s): atezolizumab. Silver Spring: US FDA; 2016.

20. Balar AV, Galsky MD, Rosenberg JE, Powles T, Petrylak DP, Bellmunt J, et al. Atezolizumab as first-line treatment in cisplatin-ineligible patients with locally advanced and metastatic urothelial carcinoma: a single-arm, multicentre, phase 2 trial. Lancet. 2017;389:67-76.

21. Avelumab (Bavencio). Highlights of prescribing information. Rockland, AM: EMD Serono, Inc.; 2017.

22. Center for Drug Evaluation and Research [CDER], US FDA. Clinical multi-discipline review: avelumab. Silver Spring: US FDA; 2017.

23. Wilkins J, Brockhaus B, Wang S, Dai H, Neuteboom B, Brar $\mathrm{S}$, et al. Population pharmacokinetic analysis of avelumab in different cancer types. J Pharmacokinet Pharmacodyn. 2017;44(1):1-143.

24. Kaufman HL, Russell J, Hamid O, Bhatia S, Terheyden P, D'Angelo SP, et al. Avelumab in patients with chemotherapyrefractory metastatic Merkel cell carcinoma: a multicentre, single-group, open-label, phase 2 trial. Lancet Oncol. 2017;17:1374-85.

25. Gulley JL, Rajan A, Spigel DR, Iannotti N, Chandler J, Wong DJL, et al. Avelumab for patients with previously treated metastatic or recurrent non-small-cell lung cancer (JAVELIN Solid Tumor): dose-expansion cohort of a multicentre, open-label, phase 1b trial. Lancet Oncol. 2017;18:599-610.

26. Apolo AB, Infante JR, Balmanoukian A, Patel MR, Wang D, Kelly K, et al. Avelumab, an anti-programmed death-ligand 1 antibody, in patients with refractory metastatic urothelial carcinoma: results from a multicenter, phase Ib study. J Clin Oncol. 2017;35:2117-24

27. Durvalumab (Iminzi). Highlights of prescribing information. Wilmington, DE: AstraZeneca Pharmaceuticals LP; 2018.

28. Baverel PG, Dubois VFS, Jin CY, Zheng Y, Song X, Jin X, et al Population pharmacokinetics of durvalumab in cancer patients and association with longitudinal biomarkers of disease status. Clin Pharmacol Ther. 2018;103(4):631-42.

29. Center for Drug Evaluation and Research [CDER], US FDA. Clinical pharmacology and biopharmaceutics review: durvalumab. Silver Spring: US FDA; 2017.

30. Powles T, O'Donnell PH, Massard C, et al. Efficacy and safety of durvalumab in locally advanced or metastatic urothelial carcinoma: Updated results from a phase 1/2 open-label study. JAMA Oncol. 2017;3:172411.

31. Nivolumab (Opdivo). Highlights of prescribing information. Princeton, NJ: Bristol-Myers Squibb Company; 2018.

32. Bajaj G, Wang X, Agrawal S, Gupta M, Roy A, Feng Y. Modelbased population pharmacokinetic analysis of nivolumab in patients with solid tumors. CPT Pharmacomet Syst Pharmacol. 2016;6:58-66.

33. Agrawal S, Feng Y, Roy A, Kollia G, Lestini B. Nivolumab dose selection: challenges, opportunities, and lessons learned for cancer immunotherapy. J Immunother Cancer. 2016;4:72.

34. Wang X, Feng Y, Bajaj G, Gupta M, Agrawal S, Yang A, et al. Quantitative characterization of the exposure-response relationship for cancer immunotherapy: a case study of nivolumab in patients with advanced melanoma. CPT Pharmacomet Syst Pharmacol. 2017;6:40-8.

35. Liu C, Yu J, Li H, Liu J, Xu Y, Song P, et al. Association of time-varying clearance of nivolumab with disease dynamics and its implications on exposure response analysis. Clin Pharmacol Ther. 2017;101:657-66.

36. Weber JS, D’Angelo SP, Minor D, Hodi FS, Gutzmer R, Neyns B, et al. Nivolumab versus chemotherapy in patients with advanced melanoma who progressed after anti-CTLA-4 treatment (CheckMate 037): a randomised, controlled, open-label, phase 3 trial. Lancet Oncol. 2017;16:375-84.

37. Topalian SL, Sznol M, McDermott DF, Kluger HM, Carvajal RD, Sharfman WH, et al. Survival, durable tumor remission, and long-term safety in patients with advanced melanoma receiving nivolumab. J Clin Oncol. 2014;32:1020-30. 
38. Pembrolizumab (Keytruda). Highlights of prescribing information. Whitehouse station, NJ: Merck \& Co., Inc.; 2016.

39. Elassaiss-Schaap J, Rossenu S, Lindauer A, Kang S, De Greef R, Sachs J, et al. Using model-based "learn and confirm" to reveal the pharmacokinetics-pharmacodynamics relationship of pembrolizumab in the KEYNOTE-001 trial. CPT Pharmacomet Syst Pharmacol. 2017;6:21-8.

40. Li H, Yu J, Liu C, Liu J, Subramaniam S, Zhao H, et al. Time dependent pharmacokinetics of pembrolizumab in patients with solid tumor and its correlation with best overall response. J Pharmacokinet Pharmacodyn. 2017;44(5):403-14.

41. Ahamadi M, Freshwater T, Prohn M, Li C, De Alwis D, De Greef $\mathrm{R}$, et al. Model-based characterization of the pharmacokinetics of pembrolizumab: a humanized anti-PD-1 monoclonal antibody in advanced solid tumors. CPT Pharmacomet Syst Pharmacol. 2017;6:49-57.

42. van Vugt M, de Greef R, Freshwater T, Mangin E, van Aarle F, Kondic A. Immunogenicity of pembrolizumab (pembro) in patients (pts) with advanced melanoma (MEL) and non-small cell lung cancer (NSCLC): Pooled results from KEYNOTE-001, 002, 006, and 010. J Clin Oncol. 2016;34:3063.

43. Chatterjee M, Elassaiss-Schaap J, Lindauer A, Turner D, Sostelly A, Freshwater T, et al. Population pharmacokinetic/pharmacodynamic modeling of tumor size dynamics in pembrolizumabtreated advanced melanoma. CPT Pharmacomet Syst Pharmacol. 2017;6:29-39.

44. Chatterjee M, Turner DC, Felip E, Lena H, Cappuzzo F, Horn $\mathrm{L}$, et al. Systematic evaluation of pembrolizumab dosing in patients with advanced non-small-cell lung cancer. Ann Oncol. 2016;27:1291-8.

45. Patnaik A, Kang SP, Rasco D, Papadopoulos KP, ElassaissSchaap J, Beeram M, et al. Phase I study of pembrolizumab (MK3475; anti-PD-1 monoclonal antibody) in patients with advanced solid tumors. Clin Cancer Res. 2015;21:4286-93.

46. Ribas A, Puzanov I, Dummer R, Schadendorf D, Hamid O, Robert $\mathrm{C}$, et al. Pembrolizumab versus investigator-choice chemotherapy for ipilimumab-refractory melanoma (KEYNOTE-002): a randomised, controlled, phase 2 trial. Lancet Oncol. 2017;16:908-18.

47. Keizer RJ, Huitema ADR, Schellens JHM, Beijnen JH. Clinical pharmacokinetics of therapeutic monoclonal antibodies. Clin Pharmacokinet. 2010;49:493-507.

48. Ipilimumab (Yervoy). Highlights of prescribing information. Princeton, NJ: Bristol-Myers Squibb Company; 2018.

49. Atezolizumab (Tecentriq). Highlights of prescribing information. San Francisco, CA: Genentech, Inc.; 2017.

50. van Brummelen EMJ, Ros W, Wolbink G, Beijnen JH, Schellens JHM. Antidrug antibody formation in oncology: clinical relevance and challenges. Oncologist. 2016;21:1260-8.

51. Zhao X, Suryawanshi S, Hruska M, Feng Y, Wang X, Shen J, et al. Assessment of nivolumab benefit-risk profile of a 240-mg flat dose relative to a $3-\mathrm{mg} / \mathrm{kg}$ dosing regimen in patients with advanced tumors. Ann Oncol. 2017;28:2002-8.

52. Kretschmer A, Schwanbeck R, Valerius T, Rösner T. Antibody isotypes for tumor immunotherapy. Transfus Med Hemother. 2017;44:320-6.

53. Junttila TT, Parsons K, Olsson C, Lu Y, Xin Y, Theriault J, et al. Superior in vivo efficacy of afucosylated trastuzumab in the treatment of HER2-amplified breast cancer. Cancer Res. 2010;70:4481-9.

54. Abuqayyas L, Balthasar JP. Application of knockout mouse models to investigate the influence of $\mathrm{Fc} \gamma \mathrm{R}$ on the tissue distribution and elimination of $8 \mathrm{C} 2$, a murine $\mathrm{IgG} 1$ monoclonal antibody. Int J Pharm. 2012;439:8-16.

55. Porporato PE. Understanding cachexia as a cancer metabolism syndrome. Oncogenesis. 2016;5:200.
56. Turner D, Kondic AG, Anderson KM, Robinson A, Garon EB, Riess JW, et al. Pembrolizumab exposure-response assessments challenged by association of cancer cachexia and catabolic clearance. Clin Cancer Res. 2018;24(23):5841-9.

57. Glassman PM, Balthasar JP. Mechanistic considerations for the use of monoclonal antibodies for cancer therapy. Cancer Biol Med. 2014;11(1):20-33.

58. MacFarlane AW, Jillab M, Plimack ER, Hudes GR, Uzzo RG, Litwin S, et al. PD-1 expression on peripheral blood cells increases with stage in renal cell carcinoma patients and is rapidly reduced after surgical tumor resection. Cancer Immunol Res. 2014;2(4):320-31.

59. Waki K, Yamada T, Yoshiyama K, Terazaki Y, Sakamoto S, Matsueda S, et al. PD-1 expression on peripheral blood T-cell subsets correlates with prognosis in non-small cell lung cancer. Cancer Sci. 2014;105:1229-35.

60. Xu P, Chen H, Chen YJ, Chen YB, Gu GH, Wu MY, Wu M, Wang XF, Zhang X. Expression of PD-1/PD-L1 in peripheral blood mononuclear cells in lung cancer patients and its biological significance. Chin J Oncol. 2013;35:910-3.

61. Buchbinder EI, Desai A. CTLA-4 and PD-1 pathways: similarities, differences, and implications of their inhibition. Am J Clin Oncol. 2016;39(1):98-106.

62. Intlekofer $\mathrm{AM}$, Thompson $\mathrm{CB}$. At the bench: preclinical rationale for CTLA-4 and PD-1 blockade as cancer immunotherapy. J Leukoc Biol. 2013;94:25-39.

63. Kang D, Wang E, Wang D, Amantea M, Hsyu P. Population pharmacokinetics (PK) of tremelimumab in patients (pts) with melanoma. J Clin Oncol. 2009;27:3048.

64. Oude Munnink T, Henstra MJ, Segerink LI, Movig KLL, Brummelhuis-Visser P. Therapeutic drug monitoring of monoclonal antibodies in inflammatory and malignant disease: translating TNF- $\alpha$ experience to oncology. Clin Pharmacol Ther. 2016;99:419-31.

65. Ratain MJ, Goldstein DA. Time is money: optimizing the scheduling of nivolumab. J Clin Oncol. 2018;36:3074-6.

66. Basak EA, Koolen SLW, Hurkmans DP, Schreurs MWJ, Bins S, Oomen-de Hoop E, et al. Correlation between nivolumab exposure and treatment outcomes in non-small-cell lung cancer. Eur J Cancer. 2019;109:12-20.

67. Gibiansky L, Gibiansky E. Target-mediated drug disposition model: approximations, identifiability of model parameters and applications to the population pharmacokinetic-pharmacodynamic modeling of biologics. Expert Opin Drug Metab Toxicol. 2009;5:803-12.

68. Becher F, Ciccolini J, Imbs D-C, Marin C, Fournel C, Dupuis $\mathrm{C}$, et al. A simple and rapid LC-MS/MS method for therapeutic drug monitoring of cetuximab: a GPCO-UNICANCER proof of concept study in head-and-neck cancer patients. Sci Rep. 2017;7:2714.

69. Beers SA, Glennie MJ, White AL. Influence of immunoglobulin isotype on therapeutic antibody function. Blood. 2016;127:1097-101.

70. Tawara T, Hasegawa K, Sugiura Y, Harada K, Miura T, Hayashi $\mathrm{S}$, et al. Complement activation plays a key role in antibodyinduced infusion toxicity in monkeys and rats. J Immunol. 2008;180:2294-8.

71. Donahue RN, Lepone LM, Grenga I, Jochems C, Fantini M, Madan RA, et al. Analyses of the peripheral immunome following multiple administrations of avelumab, a human IgG1 antiPD-L1 monoclonal antibody. J Immunother cancer. 2017;5:20.

72. Simpson TR, Li F, Montalvo-Ortiz W, Sepulveda MA, Bergerhoff $\mathrm{K}$, Arce F. Fc-dependent depletion of tumor-infiltrating regulatory $\mathrm{T}$ cells co-defines the efficacy of anti-CTLA-4 therapy against melanoma. J Exp Med. 2013;210(9):1695-710. 
73. Du X, Tang F, Liu M, Su J, Zhang Y, Wu W, et al. A reappraisal of CTLA-4 checkpoint blockade in cancer immunotherapy. Cell Res. 2018;28:416-32.

74. Schneider-Merck T, Lammerts van Bueren JJ, Berger S, Rossen K, van Berkel PHC, Derer S, et al. Human IgG2 antibodies against epidermal growth factor receptor effectively trigger antibody-dependent cellular cytotoxicity but, in contrast to IgG1, only by cells of myeloid lineage. J Immunol. 2010;184:512-20.

75. Eroglu Z, Kim DW, Wang X, Camacho LH, Chmielowski B, Seja E, et al. Long term survival with cytotoxic T lymphocyteassociated antigen 4 blockade using tremelimumab. Eur J Cancer. 2015;51:2689-97.

76. Sharma A, Subudhi SK, Blando J, Scutti J, Vence L, Wargo JA, et al. Anti-CTLA-4 immunotherapy does not deplete FOXP3+ regulatory $\mathrm{T}$ cells (Tregs) in human cancers. Clin Cancer Res. 2019;25(4):1233-8.

77. Pillai RN, Behera M, Owonikoko TK, Kamphorst AO, Pakkala $\mathrm{S}$, Belani CP, et al. Comparison of the toxicity profile of PD-1 versus PD-L1 inhibitors in non-small cell lung cancer: a systematic analysis of the literature. Cancer. 2018;124:271-7.

78. Yearley JH, Gibson C, Yu N, Moon C, Murphy E, Juco J, et al. PD-L2 expression in human tumors: relevance to anti-PD-1 therapy in cancer. Clin Cancer Res. 2017;23:3158-67.

79. Villaruz LC, Socinski MA. The clinical viewpoint: definitions, limitations of RECIST, practical considerations of measurement. Clin Cancer Res. 2013;19:2629-36.

80. Kaufman H, Schwartz LH, William WN, Sznol M, del Aguila $\mathrm{M}$, Whittington $\mathrm{C}$, et al. Evaluation of clinical endpoints as surrogates for overall survival in patients treated with immunotherapies. J Clin Oncol. 2017;35:e14557.

81. Shukuya T, Mori K, Amann JM, Bertino EM, Otterson GA, Shields PG, et al. Relationship between overall survival and response or progression-free survival in advanced non-small cell lung cancer patients treated with anti-PD-1/PD-L1 antibodies. J Thorac Oncol. 2017;11:1927-39.

82. Motzer RJ, Sharma P, Escudier BJ, McDermott DF, George S, Srinivas $\mathrm{S}$, et al. Correlation of response with overall survival (OS) for nivolumab vs everolimus in advanced renal cell carcinoma (aRCC): results from the phase III CheckMate 025 study. J Clin Oncol. 2016;34:4552.

83. Maughan B, Boucher KM, Agarwal N, Choueiri TK, Qu AQ, Vogelzang NJ, et al. Correlation of progression-free survival at 6 months (PFS6) with overall survival at 12 months (OS12) in an analysis of 10 trials of second-line therapy for advanced urothelial carcinoma (UC). J Clin Oncol. 2012;30:4525.

84. Hoos A. Evolution of end points for cancer immunotherapy trials. Ann Oncol. 2012;23:47-52.

85. Hoos A, Eggermont AMM, Janetzki S, Hodi FS, Ibrahim R, Anderson A, et al. Improved endpoints for cancer immunotherapy trials. J Natl Cancer Inst. 2010;102(18):1388-97.

86. Weber JS, Kähler KC, Hauschild A. Management of immunerelated adverse events and kinetics of response with ipilimumab. J Clin Oncol. 2012;30:2691-7.

87. Wolchok JD, Hoos A, O'Day S, Weber JS, Hamid O, Lebbé C, et al. Guidelines for the evaluation of immune therapy activity in solid tumors: immune-related response criteria. Clin Cancer Res. 2009;15:7412-20.

88. Topalian SL, Taube JM, Anders RA, Pardoll DM. Mechanismdriven biomarkers to guide immune checkpoint blockade in cancer therapy. Nat Rev Cancer. 2016;16:275-87.

89. Syed YY. Durvalumab: first global approval. Drugs. 2017;77(12):1369-76.

90. Ryan E, Sheahan K, Creavin B, Mohan HM, Winter DC. The current value of determining the mismatch repair status of colorectal cancer: a rationale for routine testing. Crit Rev Oncol Hematol. 2018;116:38-57.
91. Zappasodi R, Merghoub T, Wolchok JD. Emerging concepts for immune checkpoint blockade-based combination therapies. Cancer Cell. 2018;33(4):581-98.

92. Marshall HT, Djamgoz MBA. Immuno-oncology: emerging targets and combination therapies. Front Oncol. 2018;8:315.

93. van Hasselt JGC, Iyengar R. Systems pharmacology: defining the interactions of drug combinations. Annu Rev Pharmacol Toxicol. 2019;59:21-40.

94. Chen DS, Mellman I. Oncology meets immunology: the cancerimmunity cycle. Immunity. 2013;39:1-10.

95. Ribba B, Boetsch C, Nayak T, Grimm HP, Charo J, Evers S, et al. Prediction of the optimal dosing regimen using a mathematical model of tumor uptake for immunocytokine-based cancer immunotherapy. Clin Cancer Res. 2018;24:3325-33.

96. Ruiz-Cerdá L, Asín-Prieto E, Parra-Guillen ZP, Trocóniz IF. The long neglected player: modeling tumor uptake to guide optimal dosing. Clin Cancer Res. 2018;24:3236-8.

97. Bartelink IH, Jones EF, Shahidi-Latham SK, Lee PRE, Zheng $\mathrm{Y}$, Vicini $\mathrm{P}$, et al. Tumor drug penetration measurements could be the neglected piece of the personalized cancer treatment puzzle. Clin Pharmacol Ther. 2018. https://doi.org/10.1002/cpt.1211 (Epub 14 Aug 2018).

98. Lee JL, Kim MK, Park I, Ahn J-H, Lee DH, Ryoo HM, et al. RandomizEd phase II trial of sunitinib four weeks on and two weeks off versus two weeks on and One week off in metastatic clearcell type REnal cell carcinoma: RESTORE trial. Ann Oncol. 2015;26:2300-5.

99. Venkatakrishnan K, Friberg LE, Ouellet D, Mettetal JT, Stein A, Trocóniz IF, et al. Optimizing oncology therapeutics through quantitative translational and clinical pharmacology: challenges and opportunities. Clin Pharmacol Ther. 2015;97:37-54.

100. De Velasco G, Je Y, Bossé D, Awad MM, Ott PA, Moreira RB, et al. Comprehensive meta-analysis of key immune-related adverse events from CTLA-4 and PD-1/PD-L1 inhibitors in cancer patients. Cancer Immunol Res. 2017;5:312-8.

101. Boutros C, Tarhini A, Routier E, Lambotte O, Ladurie FL, Carbonnel F, et al. Safety profiles of anti-CTLA-4 and anti-PD-1 antibodies alone and in combination. Nat Rev Clin Oncol. 2016;13:473-86.

102. Khoja L, Day D, Wei-Wu Chen T, Siu LL, Hansen AR. Tumourand class-specific patterns of immune-related adverse events of immune checkpoint inhibitors: a systematic review. Ann Oncol. 2017;28:2377-85.

103. Robert C, Schachter J, Long GV, Arance A, Grob JJ, Mortier L, et al. Pembrolizumab versus ipilimumab in advanced melanoma. N Engl J Med. 2015;372:2521-32.

104. Larkin J, Chiarion-Sileni V, Gonzalez R, Grob JJ, Cowey CL, Lao $\mathrm{CD}$, et al. Combined nivolumab and ipilimumab or monotherapy in untreated melanoma. N Engl J Med. 2015;373:23-34.

105. Ghatalia P, Zibelman M, Geynisman DM, Plimack E. Approved checkpoint inhibitors in bladder cancer: which drug should be used when? Ther Adv Med Oncol. 2018;10:1758835918788310.

106. Andrews A. Treating with checkpoint inhibitors-figure $\$ 1$ million per patient. Am Health Drug Benefits. 2015;8(Spec Issue):9.

107. Hendrikx JJMA, Haanen JBAG, Voest EE, Schellens JHM, Huitema ADR, Beijnen JH. Fixed dosing of monoclonal antibodies in oncology. Oncologist. 2017;22:1212-21.

108. Freshwater T, Kondic A, Ahamadi M, Li CH, de Greef R, de Alwis D, et al. Evaluation of dosing strategy for pembrolizumab for oncology indications. J Immunother Cancer. 2017;5:43.

109. van Hasselt J, Gupta A, Hussein Z, Beijnen J, Schellens J, Huitema A. Disease progression/clinical outcome model for castration-resistant prostate cancer in patients treated with eribulin. CPT Pharmacomet Syst Pharmacol. 2015;4:386-95. 
110. van Hasselt JGC, van der Graaf PH. Towards integrative systems pharmacology models in oncology drug development. Drug Discov Today Technol. 2015;15:1-8.

111. van Hasselt JGC, Gupta A, Hussein Z, Beijnen JH, Schellens JHM, Huitema ADR. Population pharmacokinetic-pharmacodynamic analysis for eribulin mesilate-associated neutropenia. Br J Clin Pharmacol. 2013;76(3):412-24.

112. van Hasselt J, Gupta A, Hussein Z, Beijnen J, Schellens J, Huitema A. Integrated simulation framework for toxicity, dose intensity, disease progression, and cost effectiveness for castration-resistant prostate cancer treatment with eribulin. CPT Pharmacomet Syst Pharmacol. 2015;4:374-85.
113. van Hasselt JGC, van Eijkelenburg NKA, Beijnen JH, Schellens JHM, Huitema ADR. Optimizing drug development of anti-cancer drugs in children using modelling and simulation. Br J Clin Pharmacol. 2013;76:30-47.

114. Greenwald RJ, Freeman GJ, Sharpe AH. The B7 family revisited. Annu Rev Immunol. 2005;23:515-48.

115. Tang F, Zheng P. Tumor cells versus host immune cells: whose PD-L1 contributes to PD-1/PD-L1 blockade mediated cancer immunotherapy? Cell Biosci. 2018;8:34. 